2. To: (Receiving organization)

Mechanical Engineering \&

Inservice Inspection

5. Proj./Prog./Dept./Div.:

/NEL//

8. Originator Remarks:

Operational Test Report, Sodium Wash Station, Operational

Test Procedure

11. Receiver Remerks:
11A. Design Baseline Document?

[] Yos
3. From: (originating organization)

Mechanical Engineering \&

Inservice Inspection

6. Desion Authority/ Deaign Agent/Cog. Engr: :

IT.A. Kroner
4. Related EDT No.:

$$
N / A
$$

7. Purchase Order No.:

B6005

9. Equip./Component No.:

10. System/Bldg./Facility: //300G

12. Major. Assm. Dwg. No.:

H-3-300561 sh 1-9 Rev 0

13. Permit/Permit Application No.: $N / A$

14. Required Response Date: $N / A$

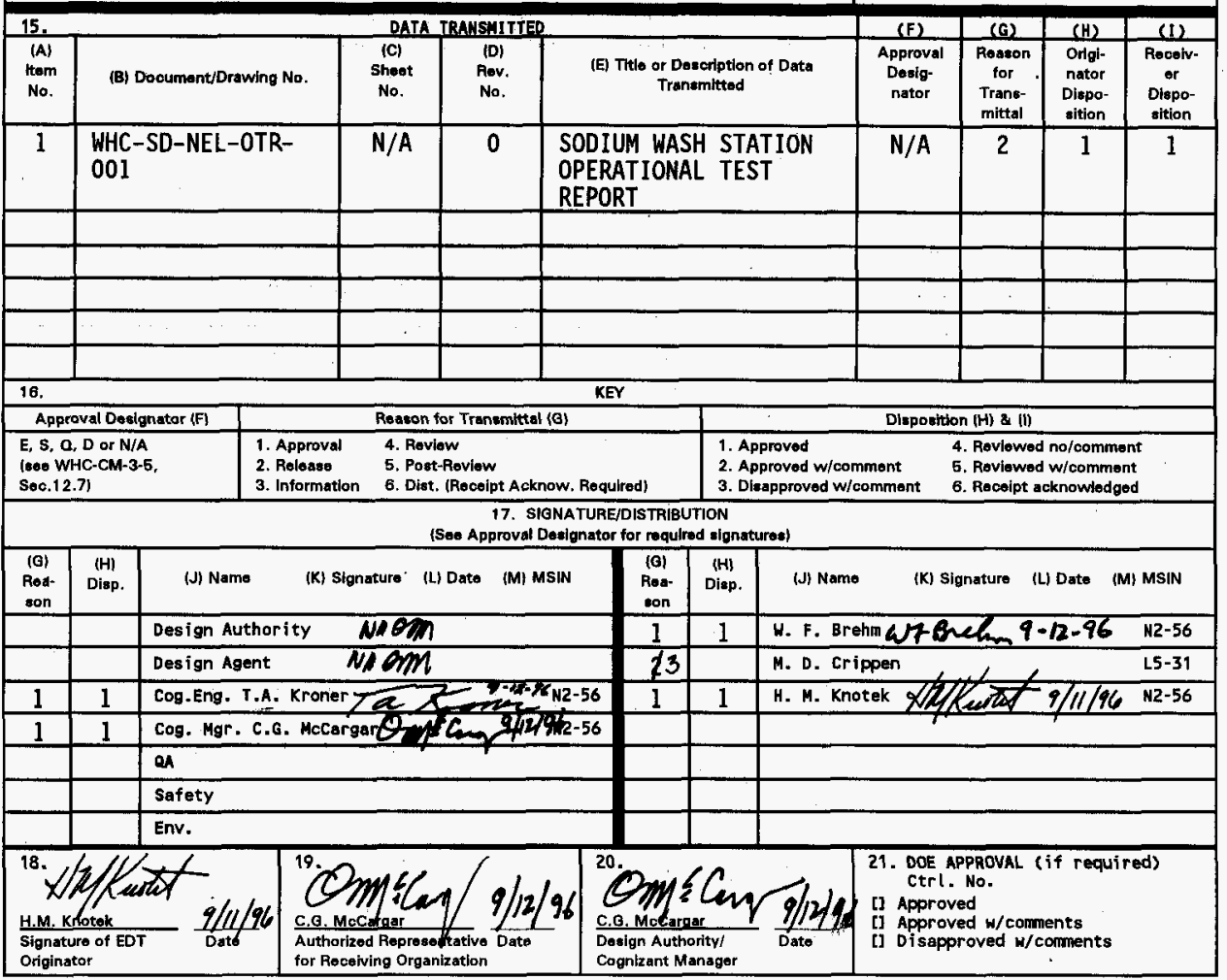




\section{Sodium Wash Station Operational Testing Report}

H. M. Knotek

Westinghouse Hanford, Richland, WA 99352

U.S. Department of Energy Contract DE-AC06-87RL10930

EDT/ECN: 617875/ UC:

Org Code: $18230 \quad$ Charge Code: B6005

B\&R Code: EX7003000 Tota1 Pages: Z3 37 seld $2 / 96$

Key Words: Operational Testing Report, Sodium Wash Station, Operational Test Procedure

Abstract: This document provides the test report for the Operability Test Procedure (OTP) performed on the Westinghouse Hanford Company developed Sodium Wash Station. The purpose of the Sodium Wash Station is to provide the capability to control and monitor the water vapor nitrogen reaction of sodium remaining in drained tanks and other components.

TRADEMARK DISCLAIMER. Reference herein to any specific commercial product, process, or service by trade name, trademark, manufacturer, or otherwise, does not necessarily constitute or imply its endorsement, recommendation, or favoring by the United States Government or any agency thereof or its contractors or subcontractors.

Printed in the United States of America. To obtain copies of this document, contact: WHC/BCS Document Control Services, P.0. Box 1970, Mailstop H6-08, Richland WA 99352, Phone (509) 372-2420; Fax (509) 376-4989.
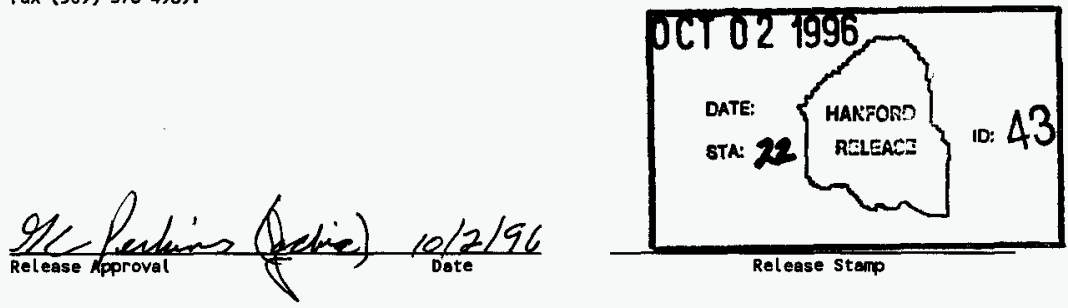

Approved for Public Release 
WHC-SD-NEL-OTR-001, Rev. 0

Page 1 of 6

\section{$1.0 \quad$ INTRODUCTION}

This document provides the test report for the Operability Test Procedure (OTP) performed on the WHC developed Sodium Wash Station. The purpose of the Sodium Wash Station is to provide the capability to control and monitor the water vapor nitrogen (WVN) reaction of sodium remaining in drained tanks and other components. This test was required to assure satisfactory operational performance of the equipment before usage. The completed OTP is attached as Appendix A. The Sodium Wetted Component Cleaning Test, Section 5.2, of the OTP was performed twice. The second run, which satisfied the objectives of the OTP, was started on August 21, 1996 and completed on August 26, 1996.

The data gathered during this test is presented in Appendix B. This data was collected by the Fluke data logger system and by the personnel performing the test. All notes taken during the test are also presented in Appendix B.

\subsection{DESCRIPTION OF TEST}

The operability test was performed July 30, 1996 through August 26, 1996, at the 335 building in the 300 area. The test was conducted by personnel from FFTF Mechanical Equipment and Inservice Inspection Engineering with Process Engineering.

The objectives of the test were to demonstrate proper function of the cleaning system. Proper function was confirmed by monitoring hydrogen evolution as the reaction/cleaning progressed, and accurate indication of the reaction endpoint which was verified by visual inspection of the test segment.

A complete description of the system, the test conditions, the equipment required, and the test procedure are stated in the OTP (Appendix A). The test segment consisted of a $90^{\circ}$ elbow approximately 4 inches in diameter and 18 inches long.

\subsection{TEST RESULTS}

The objectives of the test were satisfied. As shown in Table 1 and Figure 1 the hydrogen in nitrogen concentration approached zero as the reaction reached the endpoint. The flow rate of the nitrogen was kept at 1.0 standard cubic feet per minute (scfim) until the hydrogen evolved was near $0 \mathrm{ppm}$. The flow rate was then decreased to $0.2 \mathrm{scfm}$ to determine if the reaction was complete. The hydrogen concentration increased to approximately $150 \mathrm{ppm}$ at this flow rate. The hydrogen quickly dropped off and remained in the lower $10 \%$ of the analyzer scale $(0-50 \mathrm{ppm})$, excluding erroneous readings due to air being admitted to the sample stream, for over 1.5 hours. The test segment was then removed from the test apparatus and visually inspected. It was found that no unreacted sodium remained inside of the segment.

Fluke is a registered trademark of Fluke Corporation, Everett, WA. 
Table 1. Sodium Wash Station OTP August 26, 1996.

Time Temp (F) Hum (\%) H2 (ppm) Flow (sefm) Notes

\begin{tabular}{|c|c|c|c|c|c|}
\hline 9:30 & 87.68 & 79.55 & 137.05 & 1 & -Analyzer on line. Reaction started at $\mathbf{0 8 2 0}$. \\
\hline 9:35 & 87.68 & 80.01 & 143.79 & 1 & \\
\hline $9: 40$ & 87.70 & 80.41 & 132.74 & 1 & \\
\hline $9: 45$ & 87.70 & 80.74 & 143.42 & 1 & \\
\hline $9: 50$ & 87.69 & 81.01 & 138.15 & 1 & \\
\hline 9:55 & 87.71 & 81.30 & 135.19 & 1 & \\
\hline $10: 00$ & 87.73 & 81.59 & 124.22 & 1 & \\
\hline 10:05 & 87.73 & 81.84 & 119.46 & 1 & \\
\hline 10:10 & 87.73 & 82.06 & 112.02 & 1 & \\
\hline 10:15 & 87.72 & 82.31 & 113.35 & 1 & \\
\hline $10: 20$ & 87.63 & 82.41 & 103.58 & 1 & \\
\hline $10: 25$ & 87.60 & 82.37 & 92.40 & 1 & \\
\hline $10: 30$ & 87.62 & 82.41 & 97.03 & 1 & \\
\hline $10: 35$ & 87.59 & 82.48 & 90.18 & 1 & \\
\hline $10: 40$ & 87.59 & 82.55 & 80.66 & 1 & \\
\hline $10: 45$ & 87.56 & 82.62 & 56.81 & 1 & \\
\hline 10:50 & 87.54 & 82.71 & 30.90 & 1 & \\
\hline 10:55 & 87.54 & 82.80 & 25.10 & 1 & \\
\hline $11: 00$ & 87.54 & 82.93 & 19.16 & 1 & \\
\hline 11:05 & 87.53 & 83.08 & 7.72 & 1 & . \\
\hline 11:10 & 87.52 & 83.22 & 8.61 & 1 & \\
\hline 11:15 & 87.51 & 83.35 & 7.52 & 1 & \\
\hline $11: 20$ & 87.49 & 83.49 & 11.23 & 1 & \\
\hline $11: 25$ & 87.48 & 83.64 & 11.01 & 1 & \\
\hline $11: 30$ & 87.45 & 83.84 & -5.22 & 1 & \\
\hline $11: 35$ & 87.46 & 84.00 & 1.04 & 1 & \\
\hline 11:40 & 87.43 & 84.18 & -0.88 & 1 & \\
\hline $11: 45$ & 87.42 & 84.38 & -12.38 & 1 & \\
\hline 11:50 & 87.39 & 84.61 & -8.22 & 1 & -Hydrogen concentration below $0 \mathrm{ppm}$ \\
\hline 11:55 & 87.35 & 84.80 & 2.80 & 0.2 & flow reduced to $0.2 \mathrm{scfm}$. \\
\hline $12: 00$ & 87.29 & 84.95 & 149.77 & 0.2 & \\
\hline $12: 05$ & 87.29 & 85.11 & 87.51 & 0.2 & \\
\hline $12: 10$ & 87.24 & 85.22 & 75.67 & 0.2 & \\
\hline $12: 15$ & 87.19 & 85.33 & 38.96 & 0.2 & \\
\hline $13: 20$ & 87.18 & 85.42 & 24.39 & 0.2 & \\
\hline $12: 25$ & 87.17 & 85.54 & 17.11 & 0.2 & \\
\hline $12: 30$ & 87.13 & 85.69 & 17.57 & 0.2 & \\
\hline $12: 35$ & 87.06 & 85.81 & 19.96 & 0.2 & \\
\hline $12: 40$ & 87.06 & 85.88 & 11.24 & 0.2 & \\
\hline $12: 45$ & 87.03 & 85.97 & 10.32 & 0.2 & -Looked inside segment, no sodium could \\
\hline $12: 50$ & 87.02 & 86.08 & 289.70 & 0.2 & be seen. Reading increased due to air introduced. \\
\hline 12:55 & 86.98 & 86.16 & 139.04 & 0.2 & \\
\hline 13:00 & 86.94 & 86.22 & 33.39 & 0.2 & -Segment tipped to drain $\mathrm{NaOH}$ \\
\hline 13:05 & 86.93 & 86.27 & 29.10 & 0.2 & -Downscale calibration point checked, reading low, \\
\hline 13:10 & 86.93 & 86.32 & 50.36 & 0.2 & required adjustment. \\
\hline 13:15 & 86.97 & 86.48 & 390.39 & 0.2 & \\
\hline 13:20 & 86.80 & 86.43 & 456.22 & 0.2 & -Hydrogen reading increased, found that the \\
\hline 13:25 & 86.71 & 85.86 & 248.54 & 0.2 & Nitrogen flow had dropped below $0.2 \mathrm{scfm}$. Reading \\
\hline $13: 30$ & 86.68 & 85.10 & 26.09 & 0.2 & due to air pulled in by pump. \\
\hline $13: 35$ & 86.71 & 84.23 & 27.47 & 0.2 & \\
\hline 13:40 & 86.75 & 83.37 & 22.54 & 0.2 & \\
\hline 13:45 & 86.79 & 82.57 & 29.89 & 0.2 & \\
\hline $13: 50$ & 86.85 & 81.87 & 19.11 & 0.2 & \\
\hline
\end{tabular}



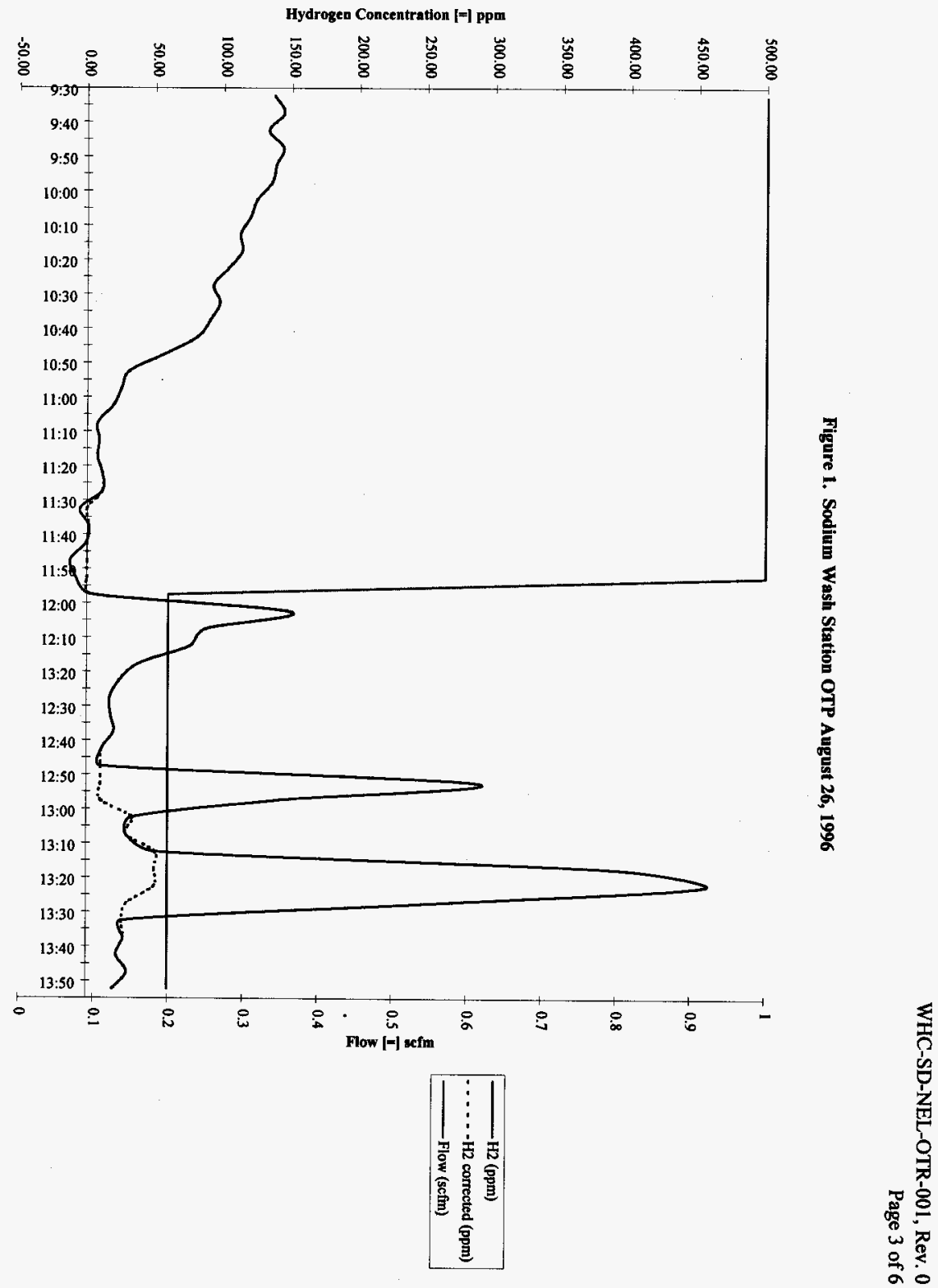
During testing it was determined that the pump B-1 pulled air into the gas vent panel at system flow rates below $0.2 \mathrm{scfm}$. The first run of the sodium wetted component test was carried out at 5 standard cubic feet per hour $(\mathrm{scfh})(.08 \mathrm{scfm})$. Data collected during this run remained above the 500 $\mathrm{ppm}$ scale of the thermal conductivity analyzer. The thermal conductivity of air is $181 \mathrm{lb} / \mathrm{hr}{ }^{\circ} \mathrm{F}$; the thermal conductivity of $500 \mathrm{ppm}$ hydrogen in nitrogen was calculated to be approximately 179 $\mathrm{lb} / \mathrm{hr}{ }^{\circ} \mathrm{F}$. This indicates that a sample of air would appear as a full scale reading on the analyzer. It was determined late in the test run that the analyzer feed was at least $20 \%$ air. The second run of the sodium wetted component test was carried out at flows above $0.2 \mathrm{scfm}(12 \mathrm{scfh})$. This required that a temporary flow indicator be installed into the system.

The sodium wash station was designed with two flow indicators in the gas supply panel. The ranges of these indicators are 100-500 scth and 0-5 scfh. It was determined during the test that the flow rate for the system had to be at least 12 scfh. A temporary flow indicator with a range of 0-1.6 scfm (0$100 \mathrm{scth}$ ) was installed into the system. A permanent flow indicator, which is currently on order, with a range of $0-100 \mathrm{scfh}$ will be installed prior to operation of the system.

The moisture column fill level determination test was modified during the performance of OTP. The OTP specifies that carryover into the component be determined at valve V-9 which is open to the atmosphere. During testing it was found that this practice could potentially damage the computer system of the sodium wash station. A clear hose was connected to the outlet of the moisture column for purposes of determining carryover. It is recommended that the clear hose remain in the system as the permanent outlet of the moisture column. This change will be incorporated into the design per ECN 708463.

The fill levels determined during this test are listed in Table 2 below. The fill levels are operational fill levels, meaning that the levels are measured while nitrogen is flowing through the column. If the column is filled without nitrogen in the system, the fill level may appear lower due to drain back of the water into the line feeding the column. The volume which drains back into the hose is dependent on the positioning of the hose. The hose should be positioned so that the water can not flow back to the gas supply panel. It should be noted that the measurements of 60 and $75 \mathrm{scfh}$ were made with a temporary flow indicator. It is recommended that these measurements be repeated once a permanent flow indicator is installed.

Table 2. Moisture column fill level

\begin{tabular}{|c|c|}
\hline Flow (scrh) & Height on sight glass \\
\hline $60^{\circ}$ & $25.75^{\circ}$ \\
\hline $75^{\circ}$ & $24.5^{\prime \prime}$ \\
\hline 100 & $15.75^{\prime \prime}$ \\
\hline
\end{tabular}

* Data point taken with temporary flow indicator.

It was determined that the moisture column was more efficient at flow rates above 60 scfh $(1.0 \mathrm{scfm})$. It was hypothesized that the higher flow rates cleared the inlet leg of the moisture column of water which had drained into the line thus utilizing the sparger pipe. At lower flow rates the nitrogen 
entered the moisture column in slugs which did not utilize the sparger pipe or packing efficiently. The flow rate at which the column begins to admit nitrogen at a steady rate is approximately $0.6-0.7$ scfm (36-42 scfh).

The humidity/temperature transmitter is located in the gas vent panel. The initial measurement of humidity, made on August 5, 1996 at a flow rate of $5 \mathrm{scfh}(.08 \mathrm{scfm})$, was $55 \%$ relative humidity at $81^{\circ} \mathrm{F}$ or $1.3 \%$ absolute humidity. After the dynamics of the moisture column and the system flow requirements were better understood the humidity measurement was reevaluated. During this process the humidity analyzer began to read a constant $93 \%$ relative humidity. Efforts to lower this reading by running dry nitrogen through the system were ineffective. The test was continued with the knowledge that the humidity analyzer would require maintenance. The transmitter, which was designed for use in HVAC systems, was operated outside of its operational range. It is assumed that the humidity remained about $1.5 \%$ absolute humidity throughout the test.

Efficiencies of various flow rates were studied as shown in Table 2. As shown in Table 2 the higher flow rates were more efficient in reacting sodium. This indicates that the residence time reduction does not inhibit the contact of the water with the sodium. It should be noted that these efficiencies should be evaluated relative to one another; the values are appropriate only for a particular surface area of sodium which was not evaluated during this test.

Table 3. Flow Rate Data Collected August 22, 1996.

\begin{tabular}{|c|c|c|}
\hline Flow rate (scfm) & Hydrogen (ppm) & Sodium Reacted $(\mathrm{lbs} / \mathrm{hr})$ \\
\hline 0.3 & 328 & $0.76 \times 10^{-3}$ \\
\hline 0.5 & 267 & $1.03 \times 10^{-3}$ \\
\hline 0.7 & 250 & $1.35 \times 10^{-3}$ \\
\hline 0.8 & 230 & $1.42 \times 10^{-3}$ \\
\hline 1.0 & 214 & $1.65 \times 10^{-3}$ \\
\hline
\end{tabular}

* Determined stoichiometrically.

\subsection{CONCLUSIONS, EXCEPTIONS, AND RECOMMENDATIONS}

The sodium wash station functioned properly in regards to monitoring, controlling, and indicating the endpoint of the reaction. However, before operation the following exceptions must be addressed.

1. Flow indication in gas supply panel below the range required.

A flow indicator with 0-100 scfh range will be installed in place of the 0-5 scfh unit currently installed in the gas supply panel. It is recommended that the flow specific tests using the temporary flow indicator be repeated. These include: The moisture column level indication test and the determination of minimum acceptable flow. 
2. The Fluke data logger requires a new battery and trouble shooting of a suspected short.

A new battery has been purchased for the data logger. In addition, downloading instructions have been added to the procedure to enable the technician to begin work in the event the data logger loses its primary programming. The suspected short was present early in the test but did not reoccur after about 8 hours of operation. The unit will be looked at by an instrument technician. The unit may only require internal cleaning.

3. The humidity/temperature transmitter does not respond to changes in humidity, reading approximately $93 \%$ under all conditions.

The transmitter was most likely saturated by the attempted humidity tests during OTP. An instrument technician will trouble shoot this instrument. At that time the limits of the unit will be determined. This transmitter may not be adequate for operation at high humidity levels but is sufficient for the lower humidities it will be subjected to during normal operation. If the humidity levels exiting the moisture column are in excess of the analyzer range a separate unit may be used to determine humidity levels. Since the data points of the stream exiting the moisture column need to be taken only once the instrument will not be installed into the system.

It is expected that during normal operation the wash station will be operated at flow rates around 100 scfh. The current design of the moisture column limits the fill level to 15 inches, or less than half of capacity, at this flow rate to avoid carry over. The reaction time required to clean a large unit with the water column at this level may be excessive. Therefore it may be beneficial to redesign the column prior to cleaning a unit with a large quantity of sodium.

It is recommended that the moisture column be replaced with a redesigned version which will saturate the nitrogen which flows through it. During this test the humidity was measured at approximately $1.3 \%$ humidity which was $55 \%$ relative humidity. To increase the humidity will require an increase in the water column height or an increase in temperature of the water in the column.

\subsection{DISPOSITION OF SODIUM WASH STATION}

When the above exceptions have been addressed the sodium wash station will be available for training. Once training has been completed the system will be placed into operation and cleaning of the sodium wetted tanks and other components will begin.

The initial operation of the system will be conducted in 8 hour shifts. During this time the system requirements to allow for 24 hour unattended operation will be determined. It is expected that the nitrogen supply will be one of the primary considerations. 
WHC-SD-NEL-OTR-001, Rev. 0

Appendix A

Page 1 of 18

APPROVAL

OPERATIONAL TESTING PROCEDURE.

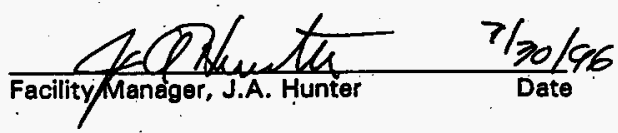

$\frac{\text { W7 Bach }}{\text { Program Leader, W.F. Bream }} \frac{7-29-96}{\text { Date }}$

$\underset{\text { Cognizant Engineer, T.A. Kroner }}{2-23: 96}$

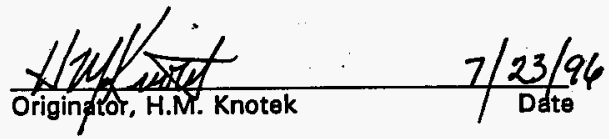


Sodium Wash Station Operational Testing page 1 of 17

\subsection{INTRODUCTION}

\subsection{PURPOSE/SCOPE}

The purpose of this Operation Test Procedure is:

1. Determine maximum fill level in moisture column.

2. Demonstrate proper function of sodium wash station at pressure and flow rate to be used during normal operation.

Proper function of the cleaning system will be determined by monitoring hydrogen evolution as reaction/cleaning progresses, ensuring the concentration of hydrogen in nitrogen approaches zero, and verifying that test segment contains no sodium by visual inspection.

\subsection{RESPONSIBILITIES}

\subsection{FFTF ENGINEERING}

FFTF Mechanical Equipment and Inservice Inspection Engineering will provide personnel for the performance and direction of the OTP.

\subsection{PROCESS ENGINEERING}

Process Engineering will provide personnel to perform the OTP.

\subsection{DESCRIPTION OF SYSTEM}

\subsection{DESIGN}

The NE Legacy Cleaning System has been designed to clean sodium wetted components in a controlled manner. The system feeds nitrogen with approximately $3 \%$ humidity into a sodium wetted component. The sodium in the component reacts with the water to produce sodium hydroxide. The evolution of hydrogen is monitored to determine when cleaning is completed.

The system consists of seven major assemblies:

- Nitrogen and Upscale Calibration Sources, H-3-300561 sheet 2

- Gas Supply Panel, H-3-300561 sheets 3 and 5

- Moisture Column, H-3-300561 sheet 6

- Gas Vent Panel, H-3-300561 sheets 3 and 5

- $\quad$ Calibration Panel, H-3-300561 sheet 5

- $\quad$ Electrical Panel, H-3-300561 sheet 8

- Data Logger and Computer System, H-3-300561 sheet 2

The interrelationship of each of the above mentioned assemblies is as shown on H-3-300560, sheet 1, "NE Legacy Loop Cleaning Gas System P\&ID." The electrical installation of thę system is as shown on H-3-300562, sheet 1, "NE Legacy Loop Cleaning Gas System Wiring Diagram." (See attached) The system requires an external, 125V, 15A, 1 phase, power source. 


\subsubsection{Nitrogen and Upscale Calibration Sources}

The nitrogen sources consist of a K-cylinder bottle containing $99.5 \%$ nitrogen and one Cryocylinder containing liquid nitrogen. The upseale calibration source consists of a $\mathrm{K}$-cylinder containing $500 \mathrm{ppm}$ hydrogen in nitrogen. The nitrogen feed to the system will be taken primarily from the liquid nitrogen cylinder. During normal operation one of the K-cylinders is used as a backup nitrogen supply.

The liquid nitrogen cylinder U-1 will be the only nitrogen source during OTP. The 500 ppm hydrogen in nitrogen will be used during the thermal conductivity analyzer checkout phase of the OTP.

\subsubsection{Gas Supply Panel}

The primary function of the gas supply panel is monitoring the pressure and flow of the nitrogen from the liquid nitrogen cylinder or K-cylinder to the moisture column and thermal conductivity analyzer. The primary stream off of the gas supply panel is fed to the lower. end of the moisture column during normal operation. Another stream is fed to the thermal conductivity analyzer as a reference stream during normal operation. A third stream is fed to the calibration panel for use as the down-scale calibration gas during calibration of the thermal conductivity analyzer.

The moisture column will be by-passed during OTP to minimize the amount of humidity introduced to the HEPA filters located in the gas vent panel.

\subsubsection{Moisture Column}

The moisture column is packed column in which the feed stream, consisting of nitrogen, is bubbled through the column. .The gas is humidified to approximately $3 \%$ moisture content. This humid nitrogen is fed to the sodium wetted component. The moisture content can be adjusted by varying the quantity of nitrogen feed which by-passes the moisture column.

\subsubsection{Gas Vent Panel}

The gas vent panel houses pressure indicators, HEPA filters, differential pressure across the filters, a vacuum pump, a drying column, and five sample points. The effluent gas off the sodium wetted component flows passively via upstream pressure into to gas vent panel. The first two sample points are located upstream and down stream of the HEPA filters. The last three sample points measure humidity and temperature, oxygen content, and hydrogen content.

The unit which analyzes for humidity and temperature is located in the gas vent panel. The units which monitor oxygen and hydrogen are located in the electrical panel. The sample stream exiting the gas vent panel is pulled through the drying column by a pump located in the calibration panel. The pump located in the gas vent panel will be used for purging the system. It will not be used during normal operation of the system. 
WHC-SD-NEL-OTR-001, Rev. 0

Appendix A

Page 4 of 18

Sodium Wash Station

Operational Testing

page 3 of 17

\subsubsection{Calibration Panel}

The calibration panel consists of a five-way switch valve, a rotary vane pump, pressure indication, a pressure relief valve set at 20 . psi, and flow control/indication. The purpose of the calibration panel is to provide conitrol and monitoring of the sample stream entering the thermal conductivity analyzer and to allow for calibration of the system at the same conditions as during normal operation.

\subsubsection{Electrical Panel}

The electrical panel provides power to the unit as well as houses the thermal conductivity analyzer and the oxygen monitor.

\subsubsection{Data Logger and Computer System}

The data logger monitors data from the humidity and temperature transmitter, located in the gas vent panel, and the thermal conductivity transmitter located in the electrical panel. This data is sent to the computer for storage in a file which can be analyzed independently of the system.

\subsection{TEST LOCATION, EQUIPMENT, AND PERSONNEL REQUIRED}

\subsection{TEST LOCATION}

Test will be conducted in the 335 building.

\subsection{EQUIPMENT}

Equipment required for OTP:

- deionized water source

1 length of pipe- sodium wetted

\subsection{PERSONNEL .}

All personnel involved in the OTP shall be trained and/or advised by FFTF Engineering on the test procedures and equipment to be used.

\subsection{OPERATION TEST PROCEDURE}

\subsection{MOISTURE COLUMN FILL LEVEL AND HUMIDITY TEST}

5.1:1 Line-up Gas Supply Panel and Moisture Column valves as shown in Table 1 and Figure 1. Set system pressure to approximately 10 psi. 

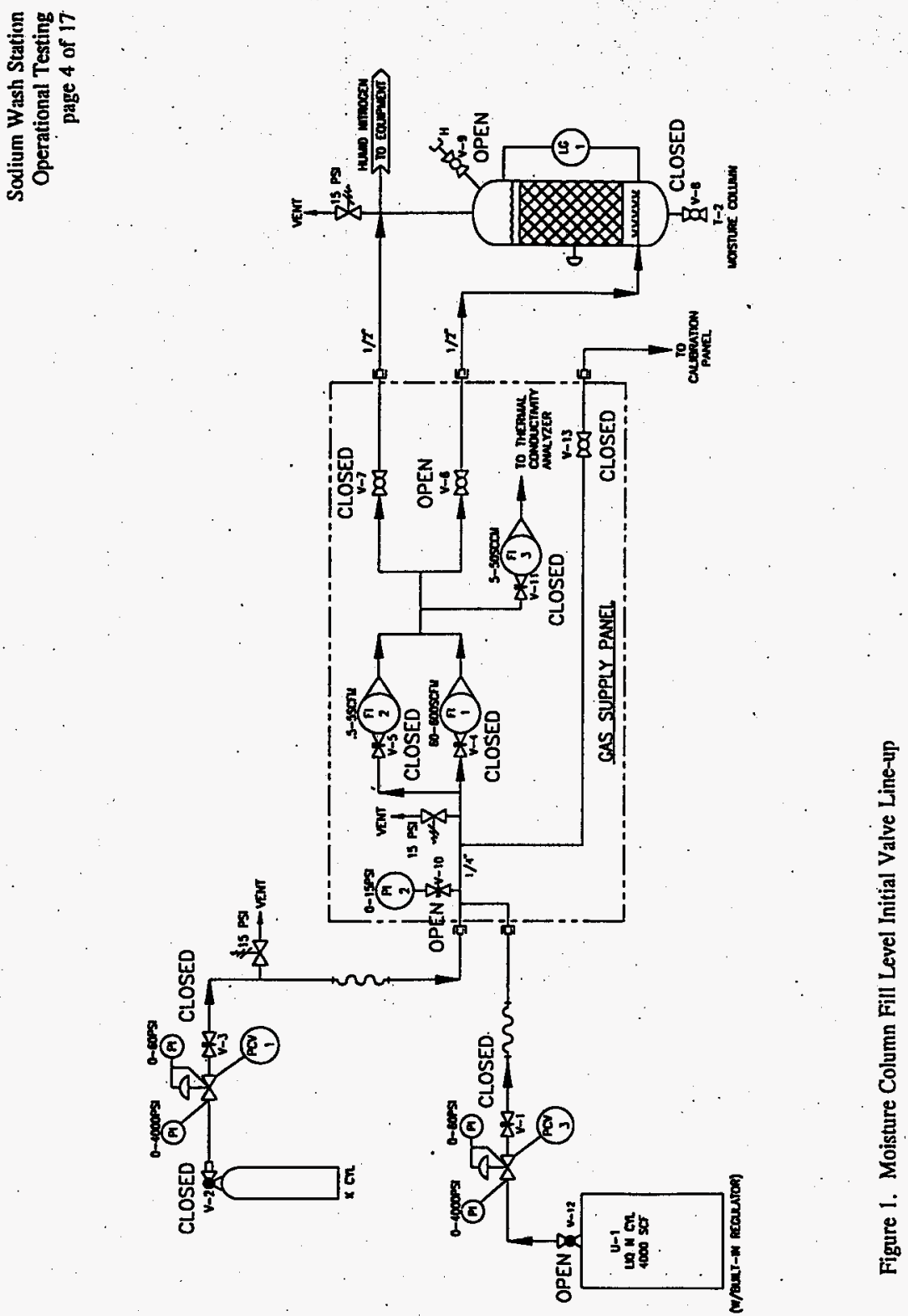
Sodium Wash Station

Operational Testing

page 5 of 17

Table 1. Moisture Column Fill Level Determination Initial Valve Line-up

\begin{tabular}{|c|c|l|}
\hline \multicolumn{3}{|c|}{ Gas Supply Panel } \\
\hline V-1 & closed & PCV-3 isolation \\
\hline V-2 & closed & Nitrogen K-cylinder isolation \\
\hline V-3 & closed & PCV-1 isolation \\
\hline V-4 & closed & FI-1 flow \\
\hline V-5 & closed & FI-2 flow \\
\hline V-6 & open & Moisture Column influent \\
\hline V-7 & closed & Moisture Column by-pass \\
\hline V-8 & closed & Moisture Column drain valve \\
\hline V-9 & open & $\begin{array}{l}\text { Moisture Column hose connector isolation (fill } \\
\text { H } 0)\end{array}$ \\
\hline V-10 & open & PI-2 isolation \\
\hline V-11 & closed & Fl-3 flow/isolation \\
\hline V-12 & open & U-1 Liquid Nitrogen Cylinder flow/isolation \\
\hline V-13 & closed & Downscale calibration gas feed isolation \\
\hline
\end{tabular}

32 psi vegulata 9 psi PI- 2 200 scfin.

5.1.2 Open valve V-1 and pressurize system to 6-10 psi with PCV-3. Adjust flow on flow indicator FI-2 to approximately 3 SCFM by adjusting valve V-5.

$$
I_{* *} \text {. } \quad 8 L \sim 1 / 2 \text { full }
$$

5.1.3 Attach fill hose to moisture column hose connector.

5.1.4 Fill moisture column approximately $3 / 4$ full with deionized water through hose fitting on moisture column.

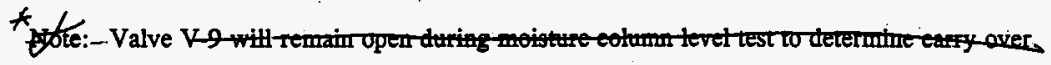

5.1.5. Disconnect water fill hose.

5.1.6 Allow nitrogen to flow until it can be assumed, per visual inspection, that no significant carryover will occur at that fill level.

5.1.7 Increase or decrease fill level and repeat until the maximum fill level is determined.

5.1.8 Mark maximum level on moisture column as "Fl-2".

* Corryover detumined using clear tubeng atteched to onttef. v-q aimed directly at computer

* this dection of test repeated with temporary flow indeciato 
5.1.9 Record maximum fill level for FI-2 from pottom of moistur oromn. Record in log book.

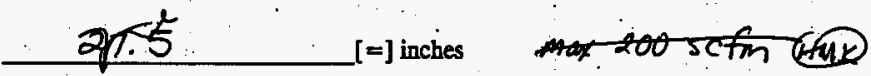

\subsubsection{Close valve V-5}

\subsubsection{Adjust flow on flow indicator FI-1. to approximately 300 SCFM by adjusting valve V-4.}

5.1.12 Allow nitrogen to flow until it can be assumed, per visual inspection, that no significant carryover will occur at that fill level.

5.1.13 Decrease fill level and repeat until the maximum fill level is determined.

5.1.14 Mark maximum level on moisture column as "FI-1".

\section{frim botton ofsigetglem MK}

5.1.15 Record maximum fill level for Fl-1 from bottomin moish Reolunn. Recont ln log book.

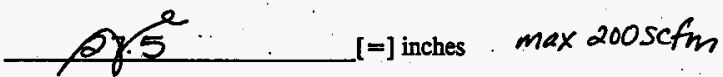

5.1.16 Close valve V-6 This did not work. Must position hoseabove wates NOTE: Close talve V-6 before stopping nitrogen flow to avoid back flow of wate from the moisture column to the gas supply panel.

5.1.17 Measure humidity exiting moisture column.

A. Attach hose exiting moisture column to quick disconnect upstream valve V-30.

B. Begin flow through gas vent panel by opening valves V-6, V-30, V-34, V-36, and V42.

CAUTION: The thermal conductivity analyzer must be disconnected prior to applying line power to the cleaning station.

C. Disconnect lead to thermal conductivity analyzer, tape lead with electrical tape.

$(\Omega)$ Verify completion of step 5.1.17.B.

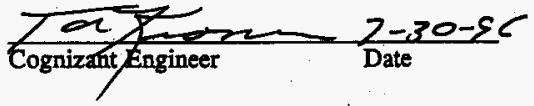

D. Apply line power to cleaning station.

* Data points taken with temporany flow indricator used for test. 
WHC-SD-NEL-OTR 001 , Rev. 0

Appendix A

Page 8 of 18

Sodium Wash Station

Operational Testing

page 7 of 17

E. On data logger, turn key to run. The logger will go through a self diagnostic and then begin to scan.

F. Turn on computer. Computer will boot directly into PROLOGR program.

Push is to G. Push F9 (2280B connection)

begin scan

H. Push F6 (REMOTE operation). Computer system will begin to monitor scan information from the data logger.

I. Record signal and humidity reading indicated by data logger.

$$
\begin{array}{ll}
3.188 & {[=] \text { volts }} \\
54.75 & {[=] \text { percent }}
\end{array}
$$

(a) $8.1^{\circ} \mathrm{F}=21.2 \circ \mathrm{C}$

J. Exit computer program, turn data logger key to OFF.

K. Disconnect line power from cleaning station.

L. Reconnect lead to thermal conductivity analyzer.

5.1.18 Close valves V-4, V-6, and V-9.

5.1.19 Refill moisture column to fill level for FI-2.

5.2 SODIUM WETTED COMPONENT CLEANING TEST

NOTE: This section of the test will be initiated at the beginning of a shift to allow sufficient time for reaction. The system will be left in a safe condition if unattended for an extended period of time.

5.2.1 Attach sodium wetter pipe segment in line of Seal Pot SP-1.

5.2.2 Verify valve line-up as shown in Tables 2 and 3, and Figures 2 and 3.

K-cylindar will be used as mitrogu some 815194 the 

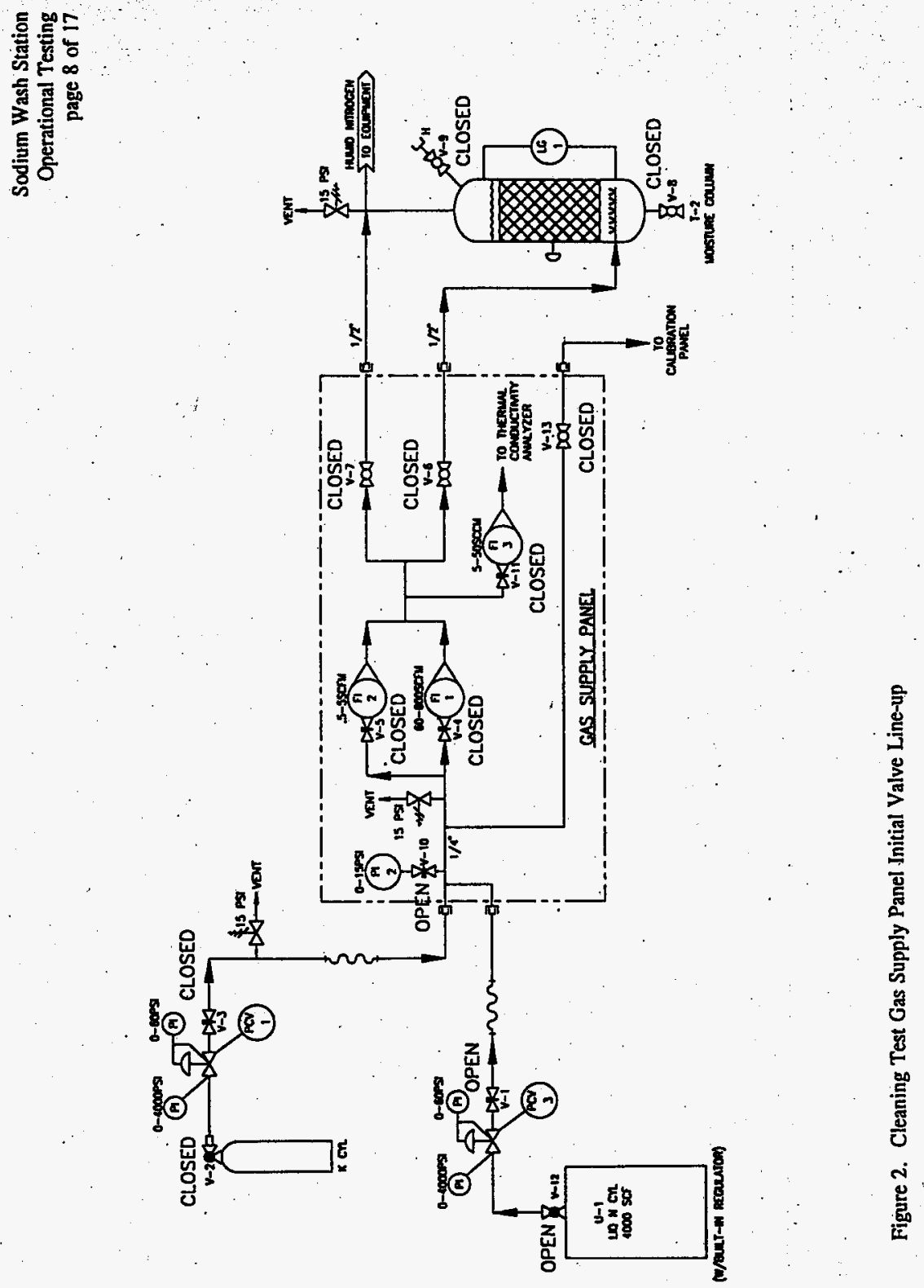
Sodium Wash Station Operational Testing page 9 of 17

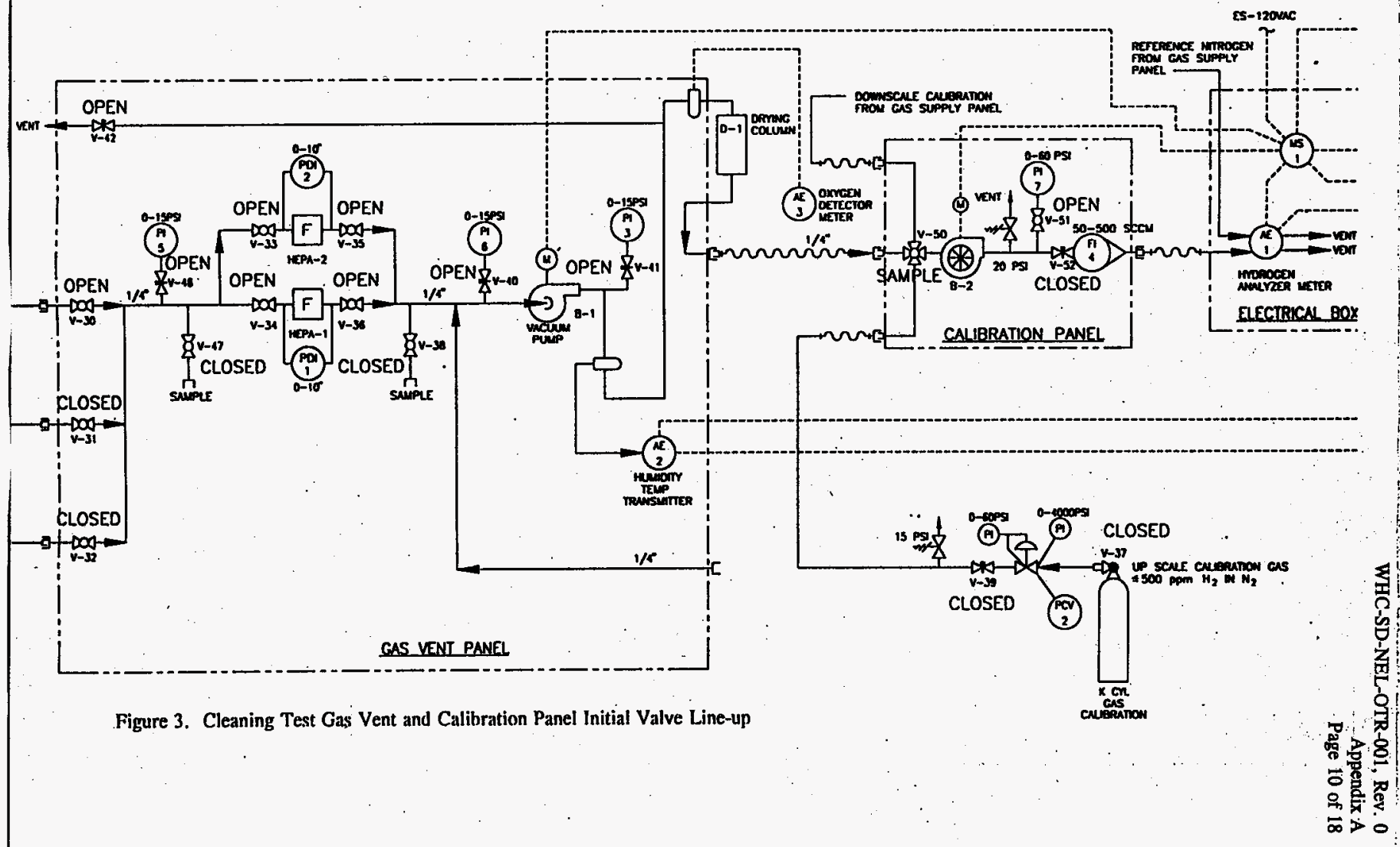


Sodium Wash Station Operational Testing page 10 of 17

Table 2. Cleaning Test Gas Supply Panel Initial Valve Line-up

\begin{tabular}{|c|c|l|}
\hline \multicolumn{2}{|c|}{ Gas Supply Panel } \\
\hline V-1 & open & PCV-3 isolation \\
\hline V-2 & closed & Nitrogen K-cylinder isolation \\
\hline V-3 & closed & PCV-1 isolation \\
\hline V-4 & closed & FI-1 flow \\
\hline V-5 & closed & Fl-2 flow \\
\hline V-6 & closed & Moisture Column influent \\
\hline V-7 & closed & Moisture Column by-pass \\
\hline V-8 & closed & Moisture Column drain valve \\
\hline V-9 & closed & Moisture Column hose connector isolation (fill $\mathrm{H}_{2} \mathrm{O}$ ) \\
\hline V-10 & open & PI-2 isolation \\
\hline V-11 & closed & FI-3 flow/isolation \\
\hline V-12 & open & U-1 Liquid Nitrogen Cylinder flow/isolation \\
\hline V-13 & closed & Downscale calibration gas feed isolation \\
\hline
\end{tabular}


Table 3. Cleaning Test Gas Vent and Calibration Panel Initial Valve Line-up

\begin{tabular}{|c|c|l|}
\hline \multicolumn{2}{|c|}{ Gas Vent Panel } \\
\hline V-30 & open & SP-1 isolation \\
\hline V-31 & closed & SP-2 isolation \\
\hline V-32 & closed & SP-3 isolation \\
\hline V-33 & open & HEPA-2 upstream isolation \\
\hline V-34 & open & HEPA-1 upstream isolation \\
\hline V-35 & open & HEPA-2 downstream isolation \\
\hline V-36 & open & HEPA-1 downstream isolation \\
\hline V-37 & closed & Up-scale calibration gas K-cylinder isolation \\
\hline V-38 & closed & Sample point downstream HEPA filters \\
\hline V-39 & closed & PCV-2 isolation \\
\hline V-40 & open & PI-6 isolation \\
\hline V-41 & open & PI-3 isolation \\
\hline V-42 & open & Gas vent panel sample gas vent \\
\hline V-46 & open & PI-5 isolation \\
\hline V-47 & closed & Sample point upstream HEPA filters \\
\hline & \multicolumn{3}{|c|}{ Calibration Panel } \\
\hline V-50 & Sample & $\begin{array}{l}\text { Thermal Conductivity Analyzer Feed } \\
\text { (Downscale/Sample/Upscale/Closed positions) }\end{array}$ \\
\hline V-51 & open & PI-7 isolation \\
\hline V-52 & closed & Fl-4 isolation \\
\hline
\end{tabular}

\subsubsection{Open valve V-7}

Note: The flow rate of nitrogen through the moisture column may be changed per cognizant engineers discretion.

5.2.4 Adjust nitrogen flow at FI-2 to approximately 5 SCFM by opening V-5

5.2.5 Open valve V-6 to start flow to moisture column

5.2.6. Close valve V-7 to divert all flow through moisture column 


\subsection{THERMAL CONDUCTIVITY ANALYZER START-UP}

CAUTION: Flow of reference and sample streams must be established prior to applying line power to thermal conductivity analyzer.

\subsubsection{Open valve V-13}

\subsubsection{Open valve V-50 to DOWNSCALE.}

5.3.3 Adjust flow in Calibration panel at flow indicator FI-4 to approximately $150 \mathrm{cc} / \mathrm{min}$ by adjusting valve V-52.

5.3.4 Adjust flow rate at flow indicator FI-3 to approximately $25 \mathrm{cc} / \mathrm{min}$.

(A) Verify flow of sample and reference streams to thermal conductivity analyzer.

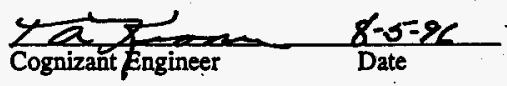

5.3.5 Apply line power to wash station.

5.3.6 Establish a sample flow at FI-4 of approximately $350 \mathrm{cc} / \mathrm{min}$ through the analyzer.

5.3:7 Adjust reference gas at FI-3 to approximately $25 \mathrm{cc} / \mathrm{min}$.

5.3.8 Verify flow rate at FI-2 at approximately 5 SCFM.

5.3.9 Allow analyzer to warm up until the on/off indicator light cycles to ensure temperature equilibration. As soon as internal temperature controller is in the control band, the heater on/off indication on the front panel should begin to illuminate intermittently.

( $)$ Verify completion of step 5.3.9

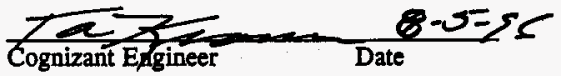

5.3.10 Initiate computer system and logging system.

The computer system and logging system are menu driven.

A. On data logger, turn key to run:- The logger will go through a self diagnostic and then begin to scan.

B. Turn on computer. Computer will boot directly into PROLOGR program.

C. Push F9 (2280B connection) 
WHC-SD-NEL-OTR-001, Rev. 0

D. Push F6 (REMOTE operation). Computer system will begin to monitor scan information from the data logger.

\subsection{THERMAL CONDUCTIVITY ANÁLYZER CALIBRATION}

5.4.1 Verify flow of approximately $350 \mathrm{cc} / \mathrm{min}$ at FI-4.

5.4.2 Set down-scale calibration point $\left(0 \mathrm{ppm} \mathrm{H}_{2}\right)$.

A. On analyzer module, set front-panel SPAN Control at normal operation setting.

B. On analyzer module, adjust front-panel ZERO Control so that reading on recorder and the front panel meter is appropriate to the down scale standard gas.

5.4.3 Adjust upscale calibration gas regulator to 10 PSI by opening valves V-39, V-37 and adjusting PCV-2.

5.4.4 Admit upscale calibration gas to the analyzer by rotating V-50 to "UPSCALE" position. Verify flow of approximately $350 \mathrm{cc} / \mathrm{min}$ at FI- W. Wait for reading on meter and recorder to stabilize.

5.4.5 Set upscale calibration point ( $500 \mathrm{ppm} \mathrm{H}_{2}$ ).

A. On analyzer module, adjust front-panel SPAN Control to the upscale standard gas.

5.4.6 Admit downscale calibration gas by adjusting V-50 to DOWNSCALE. Verify reading indicates set point of calibration within $+/-5$.

5.4.7 Admit upscale calibration gas by adjusting V-50 to UPSCALE. Verify reading indicates set point of calibration within $+1-5$.

NOTE: Repeatability of analyzer reading will constitute calibration completion.

( $)$ Verify completion of calibration.

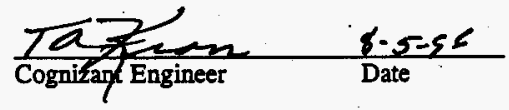

5.4.8 Initialize data logger and computer system

A. Name data file to save to disk with sufficient space

B. Begin recording on data logger and computer system by pressing record

5.4.9. Adjust flow at FI-4 to approximately $350 \mathrm{cc} / \mathrm{min}$ by adjusting valve V-52, if sufficient flow is unobtainable throttle valve V-42.

5.4.10 Monitor reaction on thermal conductivity analyzer. 
Periodically check flow rates of sample and reference streams (FI-4 and FI-3), fill level of moisture column, hydrogen evolution, and logging system for errors.

5.4.11 Record, in $\log$ book, hydrogen concentration from thermal conductivity analyzer once every one to two hours.

NOTE: Monitoring of hydrogen evolution as reaction/cleaning progresses, the concentration of hydrogen in nitrogen approaches zero, and verification of uncontaminated test segment by visual inspection, constitutes adequate operation of cleaning system.

(r) Verify adequate operation of cleaning system.

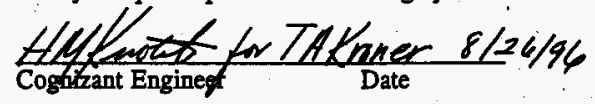

\subsection{SYSTEM SHUT-DOWN}

5.5.1 Exit computer and data logging programs.

5.5.2 Shut down power to system.

Note: The inert atmosphere should be conserved in panels by closing all valves that open the system to the atmosphere. Isolation valves upstream and downstream of HEPA filters shall be closed to decrease amount of condensate introduced to filters. K-cylinders shall be isolated.

5.5.3 Close valves as shown in Tables 4 and 5, and Figures 4 and 5.

5.5.4 Drain moisture column if it will be unused for an extended period of time. 
WHC-SD-NEL-OTR-001, Rev. 0 Appendix A

Page 16 of 18

Sodium Wash Station Operational Testing page 15 of 17

Table 4. Shut-down Gas Supply Panel Valve line-up

\begin{tabular}{|c|c|l|}
\hline \multicolumn{2}{|c|}{ Gas Supply Panel } \\
\hline V-1 & closed & PCV-3 isolation \\
\hline V-2 & closed & Nitrogen K-cylinder isolation \\
\hline V-3 & closed & PCV-1 isolation \\
\hline V-6 & closed & Moisture Column influent \\
\hline V-7 & closed & Moisture Column by-pass . \\
\hline V-8 & closed & Moisture Column drain valve \\
\hline V-9 & closed & Moisture Column hose connector isolation $\left(\right.$ fill $\left.\mathrm{H}_{2} \mathrm{O}\right)$ \\
\hline V-11 & closed & Fl-3 flow/isolation \\
\hline V-12 & closed & U-1 Liquid Nitrogen Cylinder flow/isolation \\
\hline V-13 & closed & Downscale calibration gas feed isolation \\
\hline
\end{tabular}

Table 5. Shut-down Gas Vent and Calibration Panel Valve line-up

\begin{tabular}{|c|c|l|}
\hline \multicolumn{3}{|c|}{ Gas Vent Panel } \\
\hline V-30 & closed & SP-1 isolation \\
\hline V-31 & closed & SP-2 isolation \\
\hline V-32 & closed & SP-3 isolation \\
\hline V-33 & closed & HEPA-2 upstream isolation \\
\hline V-34 & closed & HEPA-1 upstream isolation \\
\hline V-35 & closed & HEPA-2 downstream isolation \\
\hline V-36 & closed & HEPA-1 downstream isolation \\
\hline V-37 & closed & Up-scale calibration gas K-cylinder isolation \\
\hline V-38 & closed & Sample point downstream HEPA filters \\
\hline V-39 & closed & PCV-2 isolation \\
\hline V-42 & closed & Gas vent panel sample gas vent \\
\hline V-47 & closed & Sample point upstream HEPA filters \\
\hline \multicolumn{3}{|c|}{ Calibration Panel } \\
\hline V-50 & closed & $\begin{array}{l}\text { Thermal Conductivity Analyzer Feed } \\
\text { (Downscale/Sample/Upscale/Closed positions) }\end{array}$ \\
\hline V-52 & closed & FI-4 isolation \\
\hline
\end{tabular}




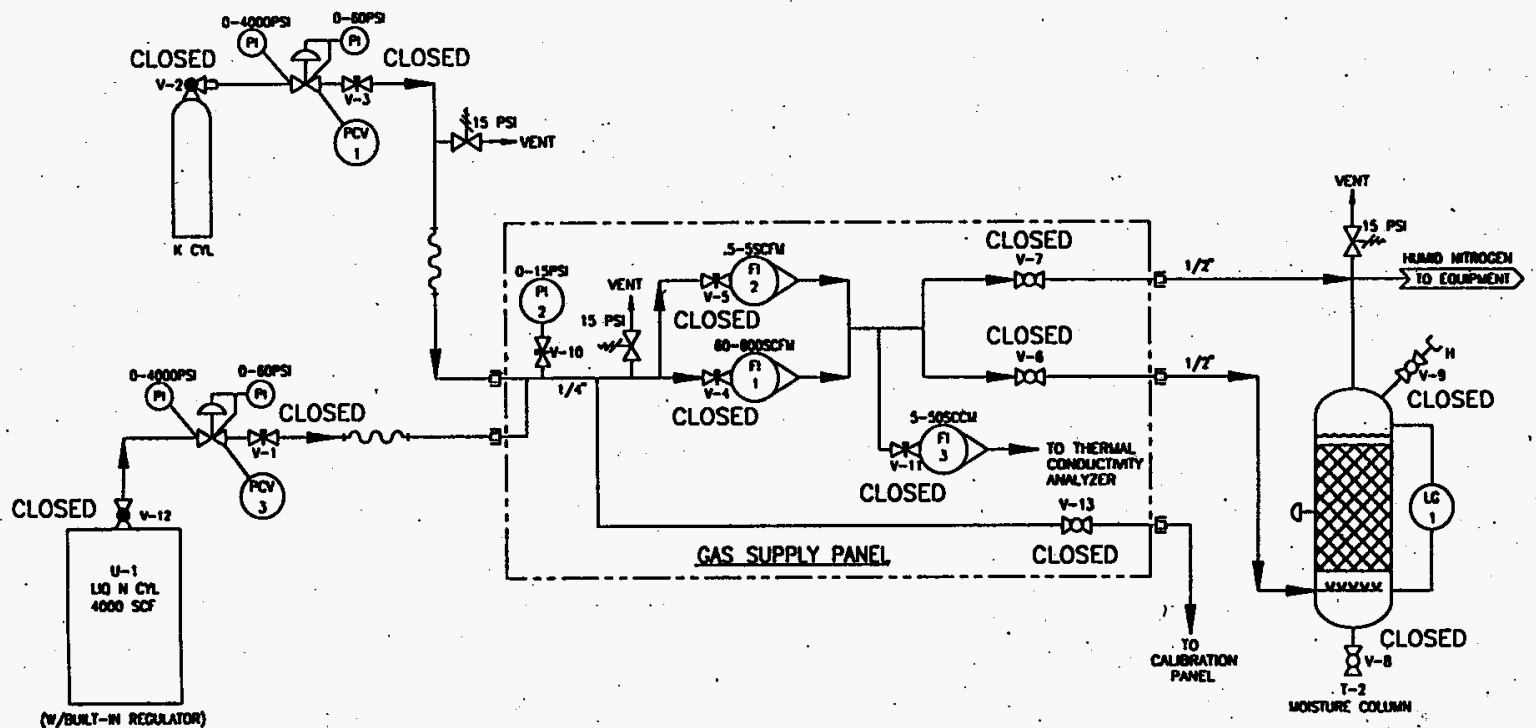

Figure 4. Shut-down Gas Supply Panel Valve Line-up 

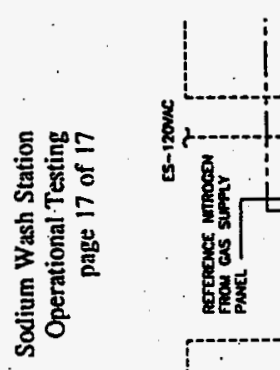

WHC-SD-NEL-OTR-001, Rev. 0 Appendix A

Page 18 of 18

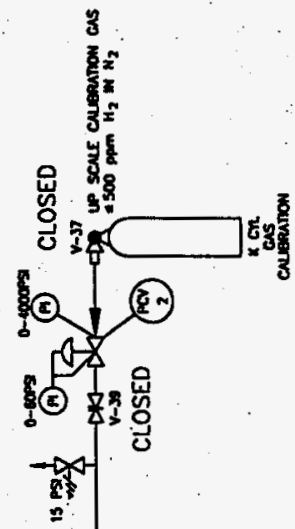


H:H. Knotek

21 Aug 94

DTP 2 test initiation - 9608 DTP. DAT

WHC-SD-NEL-OTR-001, Rev. 0

Appendix B

Cleaving segment from last testing sequence - NaH residue

Page 1 of 13

weighed ont $\mathrm{Na}$ Ep placed inside of segment $-8.4 \mathrm{~g}=0.0185 \mathrm{lb}$ Disposed of $\mathrm{NaOH}$ in absorbent.

General area clean-up for B? W tour.

Calibrate analyzer $090 \% 5180$ ppm $=0.97 \mathrm{~V}$

1220 began flow through component w/ moisture colum by paned.

$\mathrm{H}_{2}$ reads. $O$ ppm or

Flow $=.5$ SCAM $=30$ SCFH

Waited until $\mathrm{H}_{2}$ read $\mathrm{O}$ ppm. - change woflous had unterupted reading

1225 flow through moisture column. - after $\sim$. 4 min began to observer $H_{2}$ inc.

1232 flow $=$. 4 SCAM $=24$ SCFH

last humidity reading of $93 \%$ at $76 \mathrm{C}^{\circ} \mathrm{F}$ coorespto. 028 Ah. Hum.

$1245 \quad 1.86 \mathrm{~V} \mathrm{~Hz} \quad 94 \%$ at $77 . \mathrm{F}$.

$13102.77 \mathrm{~V} \mathrm{~Hz} 94 \%$ at $79 . \mathrm{F} \leftarrow$ dry bulb $\mathrm{T}_{\text {. }}$

1315 Mantanung at 200p prs

$\therefore$ lower flow to 3 CF $=18$ SCFH

$1330 \quad \mathrm{O}_{2}$ reading $00.3 \%-00.1 \%-00.0 \%$ vent nearly closed.

$1400 \quad 0 \% \mathrm{O}_{2} \quad 93.5 \%$ DP $\mathrm{F}$

$3.74 \mathrm{~V} \mathrm{H}_{2}$

1415 flow to 2 SCFM $=12$ SCFH to see if $\mathrm{H}_{2}>$ range. bubbles stopped. at 12 SCFH. Thu may sow in. b/ flow path through erlinim ymir flask e increased contact.

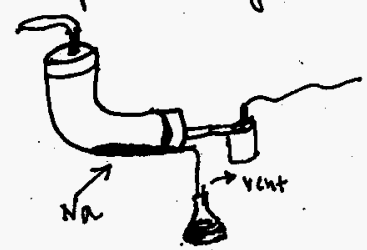

$\mathrm{H}_{2}$ reading is oscillating more than expected. Sometime n by $10 \%$ of scale. $90 \%$ scale $-100 \%$ scale.

1425 Flow de eased to. 3 SCAM $=18$ SF

1506 Flow $\Delta$ ed to by pan flow increase to .5SCFM $=30$ SCFH

$1515 \quad 2.08 \mathrm{VH}_{2} \quad 93 \%$ hum $@ 79.7^{\prime} \mathrm{F}$

$1530 \quad 1.42 \mathrm{VH}_{2}$

1535 - Scan stopped. 
22 AUG 96

Calibretion of Analeyper.
WHC-SD-NEL-OTR-001, Rev. 0

Appendix B

$$
\begin{aligned}
& 5.3 \mathrm{v}=538 \mathrm{ppm} \\
& 1.0 \mathrm{v}=0 \text { ppm }
\end{aligned} \quad \begin{aligned}
& \text { mirror edg } \\
& \text { zero }-5.62 \\
& \text { span }-3.35
\end{aligned}
$$

Page 2 of 13

0900 calibritim completo

0910 Check calibration

0.23 bypasflow to component increaxed

$\mathrm{O}_{2}$ reading $-\infty .1 \%$

Record-on. 96080TP2.DAT append.

0927 flow through column.

0941.3 SCFM $=18$ SCFH - bubbles m flaok.

pPm $H_{2}=1.31 \mathrm{~V}=40 \mathrm{pPm}-10 \mathrm{w}_{1}$ most likely hydrating. any crust that may nave formed mer niget.

humudity readug of $93 \%$ @ $74 . F-r$ ading of humiditg questimable. hes not chenged. Will maclude as exceptim to be de bugged prior to acceptance of OTP.

$1101 \quad 198 \mathrm{ppm} 92 \%$.hum $80.6^{\circ} \mathrm{F}$

$1141 \quad 320 \mathrm{ppm} 92.6 \%$ (1) $82.5 \% \mathrm{~F}$ Flow $=.3 \mathrm{sCFM}$

1211 ... mereased flow to .5SCFM to $100 \mathrm{k}$ at efficiencie

1216 296ppm - mosture colvinu souxds better at thi flow.

1230ish flow increased to . ISCFM

13i1. flow to 1 SCFM $=60$ SCFI

masture colunum soureds better. $H_{2} O$ level up on sight glan. 0 readury - $00.1 \%$

1330 higher flow rates forcung $\mathrm{NaOH}$ ont tape. cleaned up. fixed leake.

1340 lowered flow rate to . S SCFM

$1406,207 \mathrm{ppm}$

1436 193 ppm

150) $183 \mathrm{ppm}$

1513 fin decreare to. 4 sefm

1520 bypaned moisture column mcreened flow to ISCFM

1526 4leppm

1531 Hz redeng ine $\therefore$ due to fir interuption.

1536. 14 ppm off

scan off.

purge. Wft m over night

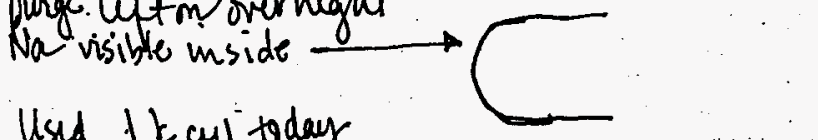

Usid $1 k$ cyl today

-1 in. in sulin col. spent. 
WHC-SD-NEL-OTR-001, Rev, 0

23 AnG96

Appendix B

Page 3 of 13

0805 Begen celibration

0858 Bequ bypan flow to comprecit.

$\mathrm{O}_{2}$ reading $0 \%$

0903 Begen flow througe crumm 0.5 SCFM

0929 Calibration completa 2 ro -5.69

0933 flow increased to

span- 4.33

.8 SCFM

$0948.85 C \mathrm{CM}, 95 \mathrm{ppm}, 92 \%$ hum, $79.8 \% \mathrm{~F}$

1023172 ppm.

1158 flow red.to .6

1230 Rau mt if $\mathrm{N}_{2}$

1245 flow at .6 SCFY

1308 316 ppm, $92 \% 79 . \mathrm{F}$

$1358 \quad 345$ ppm, $92 \%, 80 . \mathrm{F}, \mathrm{O}_{2}=0 \%$

uncrease to $.88 \mathrm{SCFM} \rightarrow 322 \mathrm{ppm}$

1423 moreaned to 1.0 scFm

1448 326 ppm.

$1500 \ldots$ Bypan morstue crlumin.

$1528 \quad 27 \%$ ppm

$153399 \mathrm{ppm}$ - flow ved to . 4 scem flow left on purge rver weekeand bette 1900 psi

botthe $22250 \mathrm{ps}$

$26 A 4496$

0.813 Calibntion started

0820 Cleaning statid (1).5 ScFs

0900 Calibration complete $\rightarrow$ zero 5.56 spar 3.72 $\mathrm{O}_{2}=0 \%$

0905 Switched $V-50$ to sample. moreand flow to 1.0 SCFM.

$0910141 \mathrm{ppm}, 81 \%$ hum, $77^{\circ} \mathrm{F}$
0920 Record on

1155 . $H_{2}$ below 0 at ISCFM reducedflor to .ZSCFM

$1245 \quad H_{2}=10 p p m$

looked unside, cant see any $\mathrm{Na}$ veadeng inc due to aci $\& 1250.289$ /pm (aii) 
WHC-SD-NEL-OTR-001, Rev. 0

Appendix B

Page 4 of 13

26 A4G96

1300

1305.

1307

1310

1320

1325

1330

1335

1350 .
33 ppm, $86 \%$ hum, $86 . F$

tipped segment to drain $\mathrm{NaOH}$

$29.10 \mathrm{pm}^{\mathrm{m}}$

Dons scale calibration point check-reading/ow. vequered adjestruent. gro. 5.62

50 ppm

$H_{2}$ reading increased- found that $N_{2}$ flow had dripped below 2 SCFM - ais had been pulled into pump. mereased flow to , SSEM reading dimpled. $250 \mathrm{ppn}$ - still error

26 ppm

$27 \mathrm{ppm}$

Record off

Opened top. 
WHC-SD-NEL-OTR-001, Rev. 0

Appendix B

Page 5 of 13

To program time:

scan must be off

$$
\begin{aligned}
& Z य 1 \\
& 2 \& H . M M \& \\
& \text { EXIT DD.MMMAYY } \\
& \text { EXIT. }
\end{aligned}
$$

beguescan.

If data logge-panel indicates "User program lost". tum key to Program'

us

Se

ie

3.

12

72

ExT

EXIT

EXIT

turn kent sen

tum computer or or get to man menu.

FF

F5 < walt for download >

F9 <wat for "online " waiting">

FI scan mill begin 
WHC-SD-NEL-OTR-001, Rev. 0

Appendix B

Page 6 of 13

Sodium Wash Station OTP August 21, 1996

Raw Data

Time Temp. (V) Hum (V) H2 (V) Temp. (F) Hum (\%) H2 (ppm) Flow (scfin) Notes

\begin{tabular}{|c|c|c|c|c|c|c|c|c|}
\hline $12: 30$ & 4.75 & 4.02 & & 93.77 & 75.56 & & 0.5 & Initiated flow through \\
\hline $12: 35$ & 4.75 & 4.05 & 1.33 & 93.81 & 76.21 & 41.89 & 0.4 & moisture column \\
\hline $12: 40$ & 4.75 & 4.07 & 1.67 & 93.83 & 76.86 & 85.68 & 0.4 & \\
\hline $12: 45$ & 4.75 & 4.10 & 1.87 & 93.85 & 77.43 & 109.23 & 0.4 & \\
\hline $12: 50$ & 4.75 & 4.12 & 1.77 & 93.85 & 77.95 & 97.04 & 0.4 & \\
\hline $12: 55$ & 4.75 & 4.14 & 1.93 & 93.82 & 78.38 & 119.32 & 0.4 & \\
\hline 13:00 & 4.75 & 4.15 & 2.08 & 93.80 & 78.76 & 135.05 & 0.4 & \\
\hline 13:05 & 4.75 & 4.16 & 2.04 & 93.78 & 79.08 & 130.97 & 0.4 & \\
\hline 13:10 & 4.75 & 4.17 & 2.78 & 93.72 & 79.29 & 230.37 & 0.4 & \\
\hline $13: 15$ & 4.75 & 4.18 & 2.53 & 93.71 & 79.53 & 199.15 & 0.3 & \\
\hline $13: 20$ & 4.75 & 4.19 & 2.65 & 93.67 & 79.65 & 224.02 & 0.3 & \\
\hline $13: 25$ & 4.75 & 4.19 & 2.73 & 93.64 & 79.69 & 208.06 & 0.3 & \\
\hline $13: 30$ & 4.74 & 4.19 & 4.06 & 93.57 & 79.66 & 384.16 & 0.3 & \\
\hline $13: 35$ & 4.74 & 4.18 & 3.64 & 93.52 & 79.53 & 326.17 & 0.3 & \\
\hline $13: 40$ & 4.74 & 4.18 & 3.72 & 93.51 & 79.52 & 339.04 & 0.3 & \\
\hline $13: 45$ & 4.74 & 4.19 & 3.75 & 93.52 & 79.65 & 341.85 & 0.3 & \\
\hline $13: 50$ & 4.74 & 4.19 & 3.48 & 93.50 & 79.73 & 307.19 & 0.3 & \\
\hline $13: 55$ & 4.74 & 4.19 & 3.61 & 93.51 & 79.83 & 325.54 & 0.3 & \\
\hline $14: 00$ & 4.74 & 4.20 & 3.74 & 93.51 & 79.96 & 349.13 & 0.3 & \\
\hline 14:05 & 4.74 & 4.20 & 3.38 & 93.49 & 80.02 & 297.63 & 0.3 & \\
\hline 14:10 & 4.74 & 4.20 & 3.65 & 93.46 & 80.05 & 337.65 & 0.3 & \\
\hline $14: 15$ & 4.74 & 4.20 & 5.08 & 93.44 & 80.05 & 528.36 & 0.2 & \\
\hline $14: 20$ & 4.74 & 4.20 & 4.36 & 93.43 & 80.05 & 426.45 & 0.2 & \\
\hline $14: 25$ & 4.74 & 4.20 & 4.96 & 93.41 & 80.06 & 508.89 & 0.3 & \\
\hline $14: 30$ & 4.73 & 4.20 & 3.53 & 93.37 & 80.03 & 314.47 & 0.3 & \\
\hline 14:35 & 4.73 & 4.20 & 3.64 & 93.33 & 79.88 & 326.06 & 0.3 & \\
\hline $14: 40$ & 4.73 & 4.19 & 3.40 & 93.33 & 79.72 & 298.23 & 0.3 & \\
\hline $14: 45$ & 4.73 & 4.18 & 4.78 & 93.35 & 79.54 & 467.28 & 0.3 & \\
\hline 14:50 & 4.73 & 4.18 & $4.45^{\circ}$ & 93.35 & 79.43 & 418.99 & 0.3 & \\
\hline $14: 55$ & 4.74 & 4.18 & 3.55 & 93.38 & 79.54 & 317.34 & 0.3 & \\
\hline $15: 00$ & 4.74 & 4.19 & 3.49 & 93.37 & 79.67 & 311.65 & 0.3 & \\
\hline 15:05 & 4.73 & 4.19 & 3.72 & 93.35 & 79.70 & 332.07 & 0.5 & Flow path by-pass moisture \\
\hline $15: 10$ & 4.73 & 4.19 & 2.87 & 93.32 & 79.71 & 227.93 & 0.5 & column. \\
\hline $15: 15$ & 4.73 & 4.19 & 2.08 & 93.31 & 79.71 & 135.39 & 0.5 & \\
\hline $15: 20$ & 4.73 & 4.19 & 1.61 & 93.29 & 79.68 & 75.96 & 0.5 & \\
\hline $15: 25$ & 4.73 & 4.19 & 1.58 & 93.29 & 79.65 & 72.79 & 0.5 & \\
\hline $15: 30$ & 4.73 & 4.19 & 1.42 & 93.32 & 79.77 & 52.75 & 0.5 & \\
\hline $15: 35$ & 4.73 & 4.21 & 1.48 & 93.33 & 80.16 & 60.45 & 0.5 & \\
\hline
\end{tabular}



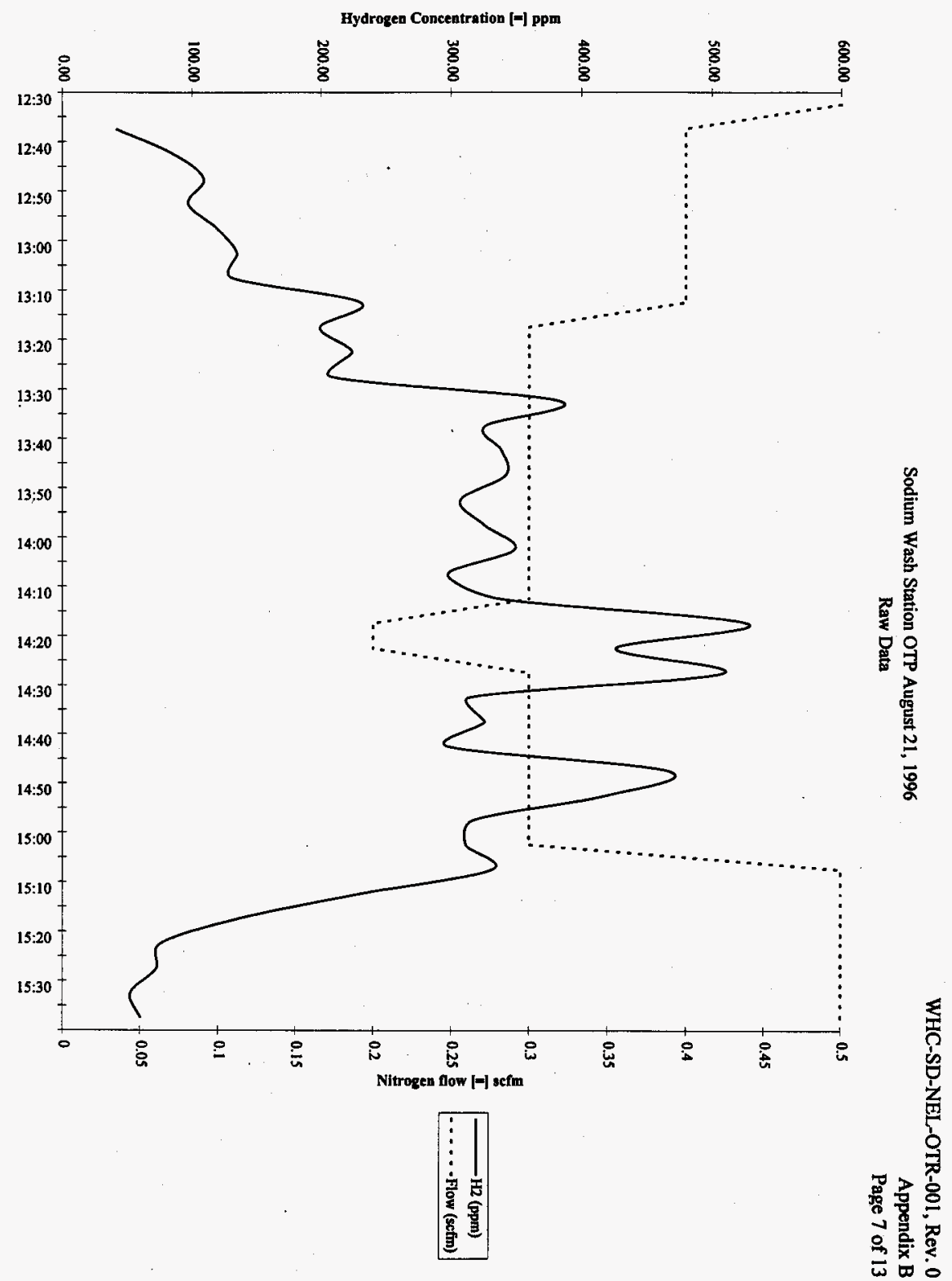
Time Temp (V) Hum (V) H2 (V) Temp (F) Hum (\%) H2 (ppm) Flow (scfm) Notes

\begin{tabular}{|c|c|c|c|c|c|c|c|c|}
\hline $9: 26$ & 4.72 & 3.89 & 1.15 & 93.09 & 72.22 & 19.74 & 0.3 & Initisted flow through \\
\hline $9: 31$ & 4.73 & 3.91 & 1.55 & 93.13 & $\mathbf{7 2 . 8 1}$ & 69.08 & 0.3 & moisture column. \\
\hline $9: 36$ & 4.73 & 3.94 & 1.36 & 93.18 & 73.57 & 45.47 & 0.3 & \\
\hline $9: 41$ & 4.73 & 3.98 & 1.32 & 93.23 & 74.43 & 39.73 & 0.3 & \\
\hline $9: 46$ & 4.73 & 4.01 & 1.41 & 93.24 & 75.27 & 51.42 & 0.3 & \\
\hline $9: 51$ & 4.73 & 4.04 & 1.44 & 93.23 & 75.99 & 54.85 & 0.3 & \\
\hline $9: 56$ & 4.73 & 4.07 & 1.45 & 93.22 & 76.65 & 55.73 & 0.3 & \\
\hline $10: 01$ & 4.73 & 4.09 & $1.5 t$ & 93.20 & 77.23 & 62.29 & 0.3 & \\
\hline $10: 06$ & 4.73 & 4.11 & 1.55 & 93.16 & 77.74 & 68.25 & 0.3 & \\
\hline $10: 11$ & 4.72 & 4.13 & 1.57 & 93.12 & 78.17 & 71.15 & 0.3 & \\
\hline $10: 16$ & 4.72 & 4.14 & 1.64 & 93.10 & 78.57 & 80.12 & 0.3 & \\
\hline $10: 21$ & 4.72 & 4.16 & 1.70 & 93.05 & 78.93 & 87.10 & 0.3 & . \\
\hline $10: 26$ & 4.72 & 4.17 & 1.90 & 93.01 & 79.23 & 112.48 & 0.3 & \\
\hline $10: 31$ & 4.72 & 4.18 & 1.95 & 92.97 & 79.49 & 119.73 & 0.3 & \\
\hline $10: 36$ & 4.72 & 4.19 & 2.12 & 92.92 & 79.68 & 138.64 & 0.3 & . \\
\hline $10: 41$ & 4.72 & 4.19 & 2.19 & 92.90 & 79.81 & 149.12 & 0.3 & \\
\hline $10: 46$ & 4.72 & 4.20 & 2.29 & 92.89 & 79,97 & 161.15 & 0.3 & \\
\hline $10: 51$ & 4.72 & 4.21 & 2.31 & 92.90 & 80.18 & 164.90 & 0.3 & \\
\hline $10: 56$ & 4.71 & 4.22 & 2.52 & 92.87 & 80.39 & 188.74 & 0.3 & \\
\hline $11: 01$ & 4.71 & 4.23 & 2.61 & 92.86 & 80.63 & 198.31 & 0.3 & \\
\hline $11: 06$ & 4.71 & 4.23 & 2.85 & 92.85 & 80.88 & 229.06 & 0.3 & \\
\hline $11: 11$ & 4.71 & 4.25 & 3.03 & 92.83 & 81.13 & 248.47 & 0.3 & \\
\hline $11: 16$ & 4.71 & 4.25 & 3.17 & 92.80 & 81.37 & 272.32 & 0.3 & \\
\hline $11: 21$ & 4.71 & 4.26 & 3.07 & 92.80 & 81.63 & 258.62 & 0.3 & \\
\hline $11: 26$ & 4.71 & 4.27 & 3.03 & 92.78 & 81.88 & 253.42 & 0.3 & \\
\hline $11: 31$ & 4.71 & 4.28 & 3.26 & 92.75 & 82.11 & 281.14 & 0.3 & \\
\hline $11: 36$ & 4.71 & 4,29 & 3.36 & 92.73 & 82.35 & 293.39 & 0.3 & \\
\hline $11: 41$ & 4.71 & 4.30 & 3.57 & 92.70 & 82.59 & 320.36 & 0.3 & \\
\hline $11: 46$ & 4.71 & 4.31 & 3.43 & 92.67 & 82.79 & 304.22 & 0.3 & \\
\hline $11: 51$ & 4.71 & 4.32 & 3.37 & 92.65 & 82.97 & 297.58 & 0.3 & \\
\hline $11: 56$ & 4.71 & 4.33 & 3.52 & 92.64 & 83.17 & 315.86 & 0.3 & \\
\hline $12: 01$ & 4.71 & 4.34 & 3.51 & 92.62 & 83.41 & 313.67 & 0.3 & \\
\hline $12: 06$ & 4.70 & 4.34 & 5.05 & 92,59 & 83.61 & 503.04 & 0.3 & \\
\hline $12: 11$ & 4.70 & 4.35 & 3.62 & 92.56 & 83.79 & 328.20 & 0.5 & Data collection for flow \\
\hline $12: 16$ & 4.70 & 4.36 & 3.38 & 92.54 & 83.99 & 296.44 & 0.5 & efficiency study. \\
\hline $12: 21$ & 4.70 & $\mathbf{4 . 3 7}$ & 3.27 & 92.53 & 84.19 & 285.54 & 0.5 & \\
\hline $12: 26$ & 4.70 & 4.38 & 3.14 & 92.52 & 84.44 & 267.56 & 0.5 & \\
\hline $12: 31$ & 4.70 & 4.39 & 3.13 & 92.49 & 84.67 & 261.56 & 0.7 & \\
\hline $12: 36$ & 4.70 & 4.40 & 3.39 & 92.44 & 84.88 & 297.55 & 0.7 & \\
\hline $12: 41$ & 4.70 & 4.40 & 3.28 & 92.43 & 85.09 & 284.74 & 0.7 & \\
\hline $12: 46$ & 4.70 & 4.41 & 3.15 & 92.41 & 85.27 & 265.91 & 0.7 & \\
\hline $12: 51$ & 4.70 & 4.42 & 3.10 & 92.41 & 85.46 & 257.83 & 0.7 & \\
\hline $12: 56$ & 4.70 & 4,43 & 2.97 & 92.38 & 85.67 & 244.15 & 0.7 & \\
\hline $13: 01$ & 4.69 & 4.43 & 3.15 & 92.35 & 85.86 & 270.33 & 0.7 & \\
\hline $13: 06$ & 4.69 & 4.44 & 3.02 & 92.33 & 86.06 & 250.87 & 0.7 & \\
\hline $13: 11$ & 4.69 & 4.45 & 3.10 & 92.28 & 86.22 & 261.44 & 1 & \\
\hline $13: 16$ & 4.69 & 4.45 & 2.84 & 92.26 & 86.28 & 228.95 & 1 & \\
\hline $13: 21$ & 4.69 & 4.45 & 3.13 & 92.27 & 86.33 & 265.25 & 1 & \\
\hline $13: 26$ & 4.69 & 4.46 & 3.31 & 92.27 & 86.39 & 284.11 & 1 & \\
\hline $13: 31$ & 4.69 & 4.46 & 2.85 & 92.30 & 86.52 & 229.59 & 1 & \\
\hline $13: 36$ & 4.69 & 4.47 & 2.76 & 92.29 & 86.65 & 218.70 & 1 & \\
\hline $13: 41$ & 4.69 & 4.47 & 2.70 & 92.24 & 86.66 & 214.15 & 0.8 & \\
\hline $13: 46$ & 4.69 & 4.47 & 2.86 & 92.26 & 86,64 & 231.95 & 0.8 & \\
\hline $13: 51$ & 4.69 & 4.47 & 2.81 & 92,33 & 86.81 & 225.75 & 0.8 & \\
\hline $13: 56$ & 4.69 & 4.47 & 2.83 & 92.33 & 86.83 & 229.45 & 0.8 & \\
\hline $14: 01$ & 4.69 & 4.47 & 2.71 & 92.28 & 86.63 & 215.58 & 0.8 & \\
\hline $14: 06$ & 4.69 & 4.45 & 2.66 & 92.26 & 86.28 & 207.96 & 0.8 & \\
\hline $14: 11$ & 4.69 & 4.43 & 2.65 & 92.26 & 85.84 & 204.81 & 0.8 & \\
\hline $14: 16$ & 4.69 & 4.42 & 2.56 & 92.28 & 85.39 & 197.01 & 0.8 & \\
\hline $14: 21$ & 4.69 & 4.40 & 2.60 & 92.28 & 85.00 & 198.52 & 0.8 & \\
\hline $14: 26$ & 4.69 & 4.38 & 2.47 & 92.28 & $\$ 4.60$ & 184.23 & 0.8 & \\
\hline $14: 31$ & 4.69 & 4.37 & 2.54 & 92.27 & 84.23 & 192.49 & 0.8 & \\
\hline $14: 36$ & 4.69 & 4.36 & 2.55 & 92.26 & 83.89 & 193.20 & 0.8 & \\
\hline $14: 41$ & 4.69 & 4.34 & 2.53 & 92.31 & 83.61 & 190.47 & 0.8 & \\
\hline $14: 46$ & 4.69 & 4.33 & 2.50 & 92.29 & 83.34 & 188.48 & 0.8 & \\
\hline $14: 51$ & 4.69 & 4.32 & 2.48 & 92.30 & 83.06 & 184.72 & 0.8 & \\
\hline $14: 56$ & 4.69 & 4.31 & 2.44 & 92.31 & 82.86 & 179.37 & 0.8 & \\
\hline $15: 01$ & 4.69 & 4.31 & 2.47 & 92.30 & 82.66 & 183.68 & 0.8 & \\
\hline 15:06 & 4.69 & 4.30 & 2.43 & 92.30 & 82.50 & 180.77 & 0.8 & \\
\hline 15:11 & 4.69 & 4.29 & 2.43 & 92.30 & 82.31 & 181.49 & 0.8 & \\
\hline $15: 16$ & 4.69 & 4.29 & 2.57 & 92.30 & 82.20 & 196.69 & 0.6 & \\
\hline $15: 21$ & 4.69 & 4.28 & 2.51 & 92.30 & 82.06 & 188.10 & 1 & By-passed moisture column. \\
\hline $15: 26$ & 4.69 & 4.28 & 1.39 & 92.27 & 81.88 & 46.15 & 1 & \\
\hline $15: 31$ & 4.69 & 4.27 & 1.66 & 92.27 & 81.74 & 88.44 & 1 & Flow interuption. \\
\hline 15:36 & 4,69 & 4.27 & 1.11 & 92.27 & 81.63 & 14.17 & 1 & \\
\hline
\end{tabular}




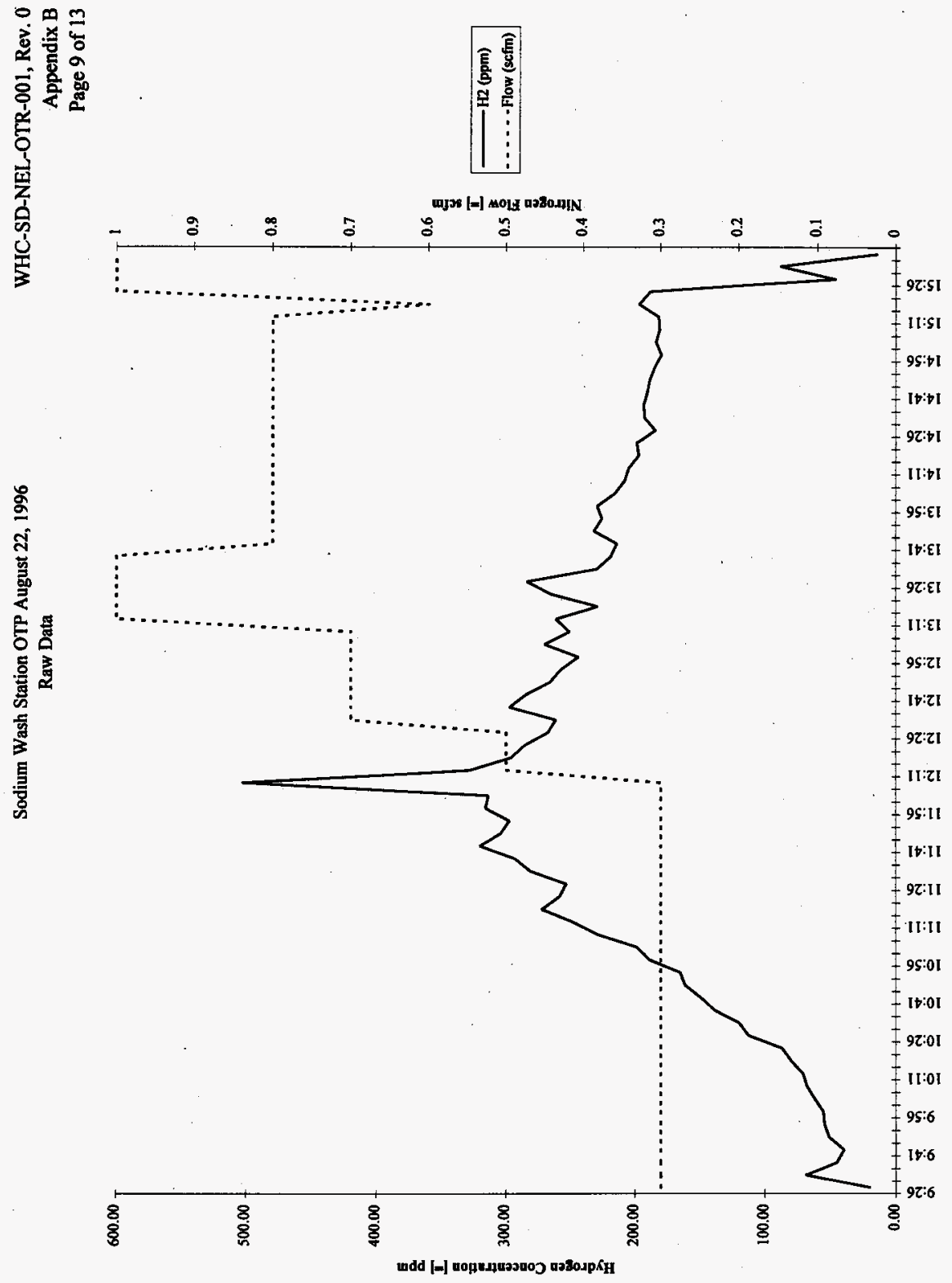




\section{Raw Data}

Time Temp (V) Hum (V) H2 (V) Temp (F) Hum (\%) H2 (ppm) Flow (scfm) Notes

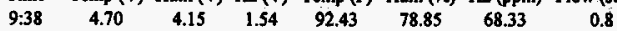

$\begin{array}{llllllll}9.43 & 4.70 & 4.17 & 1.64 & 92.41 & 79.33 & 80.81 & 0.8\end{array}$

$\begin{array}{llllllll}9: 48 & 4.70 & 4.19 & 1.76 & 92.41 & 79.86 & 95.53 & 0.8\end{array}$

$\begin{array}{llllllll}9.53 & 4.69 & 4.21 & 1.95 & 92.37 & 80.24 & 117.97 & 0.8\end{array}$

$\begin{array}{llllllll}9.58 & 4.69 & 4.21 & 2.05 & 92.30 & 80.35 & 132.02 & 0.8\end{array}$

$\begin{array}{llllllll}10: 03 & 4.69 & 4.21 & 2.13 & 92.24 & 80.30 & 143.08 & 0.8\end{array}$

$\begin{array}{llllllll}10: 08 & 4.69 & 4.21 & 2.21 & 92.19 & 80.26 & 151.84 & 0.8\end{array}$

$\begin{array}{llllllll}10: 13 & 4.69 & 4.22 & 2.30 & 92.21 & 80.46 & 162.34 & 0.8\end{array}$

$\begin{array}{llllllll}10: 18 & 4.69 & 4.23 & 2.37 & 92.21 & 80.66 & 172.35 & 0.8\end{array}$

$\begin{array}{llllllll}10: 23 & 4.69 & 4.23 & 2.37 & 92.17 & 80.65 & 172.46 & 0.8\end{array}$

$\begin{array}{llllllll}10: 28 & 4.68 & 4.22 & 2.31 & 92.11 & 80.48 & 163.63 & 0.8\end{array}$

$\begin{array}{llllllll}10: 33 & 4.68 & 4.21 & 2.31 & 92.10 & 80.32 & 163.99 & 0.8\end{array}$

$\begin{array}{llllllll}10: 38 & 4.68 & 4.22 & 2.35 & 92.12 & 80.49 & 167.59 & 0.8\end{array}$

$\begin{array}{llllllll}10: 41 & 4.68 & 4.22 & 2.42 & 92.11 & 80.56 & 177.40 & 0.8\end{array}$

$\begin{array}{llllllll}10: 46 & 4.68 & 4.22 & 2.38 & 92.09 & 80.56 & 172.06 & 0.8\end{array}$

$\begin{array}{lllllllll}10: 51 & 4.68 & 4.22 & 2.40 & 92.06 & 80.46 & 176.86 & 0.8\end{array}$

$\begin{array}{llllllll}10: 56 & 4.68 & 4.22 & 2.41 & 92.06 & 80.39 & 174.92 & 0.8\end{array}$

$\begin{array}{llllllll}11: 01 & 4.68 & 4.22 & 2.27 & 92.07 & 80.50 & 158.03 & 0.8\end{array}$

$\begin{array}{llllllll}11: 06 & 4.68 & 4.22 & 2.27 & 92.06 & 80.53 & 158.78 & 0.8\end{array}$

$\begin{array}{llllllll}11: 11 & 4.68 & 4.22 & 2.29 & 92.03 & 80.49 & 162.22 & 0.8\end{array}$

$\begin{array}{llllllll}11: 16 & 4.68 & 4.22 & 2.24 & 92.02 & 80.42 & 154.47 & 0.8\end{array}$

$\begin{array}{llllllll}11: 21 & 4.68 & 4.21 & 2.19 & 92.04 & 80.36 & 148.98 & 0.8\end{array}$

$\begin{array}{llllllll}11: 26 & 4.68 & 4.21 & 2.17 & 92.01 & 80.28 & 148.20 & 0.8 \\ 11.31 & 4.68 & 4.21 & 2.23 & 92.00 & 80.22 & 152.90 & 0.8\end{array}$

$\begin{array}{llllllll}11: 36 & 4.68 & 4.22 & 2.12 & 92.01 & 80.41 & 140.07 & 0.8\end{array}$

$\begin{array}{llllllll}11: 41 & 4.68 & 4.22 & 2.03 & 91.99 & 80.62 & 130.19 & 0.8\end{array}$

$\begin{array}{llllllll}11: 46 & 4.68 & 4.22 & 2.15 & 91.92 & 80.45 & 144.02 & 0.8\end{array}$

$\begin{array}{llllllll}11: 51 & 4.68 & 4.22 & 2.12 & 91.96 & 80.39 & 139.12 & 0.8\end{array}$

$\begin{array}{llllllll}11: 56 & 4.68 & 4.22 & 2.10 & 91.96 & 80.41 & 137.66 & 0.8\end{array}$

$\begin{array}{llllllll}12: 01 & 4.68 & 4.21 & 1.91 & 91.95 & 80.33 & 113.43 & 0.6\end{array}$

$\begin{array}{llllllll}12: 06 & 4.68 & 4.21 & 1.92 & 91.96 & 80.34 & 114.01 & 0.6\end{array}$

$\begin{array}{llllllll}12: 11 & 4.68 & 4.21 & 1.66 & 91.94 & 80.37 & 82.49 & 0.6\end{array}$

$\begin{array}{llllllll}12: 16 & 4.68 & 4.21 & 1.12 & 91.90 & 80.32 & 14.39 & 0.6\end{array}$

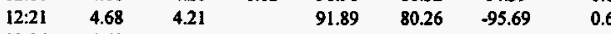

$\begin{array}{llllllll}12: 26 & 4.68 & 4.21 & 2.85 & 91.92 & 80.24 & 288.95 & 0\end{array}$

$\begin{array}{llllllll}12: 48 & 4.69 & 4.15 & 2.60 & 92.26 & 78.65 & 201.76 & 0.6\end{array}$

$\begin{array}{llllllll}12: 53 & 4.69 & 4.16 & 3.11 & 92.29 & 78.97 & 264.18 & 0.6\end{array}$

$\begin{array}{lllllllll}12: 58 & 4.69 & 4.17 & 3.23 & 92.23 & 79.18 & 278.85 & 0.8\end{array}$

$\begin{array}{llllllll}13: 03 & 4.69 & 4.18 & 3.26 & 92.19 & 79.40 & 282.27 & 0.8\end{array}$

$\begin{array}{llllllll}13: 08 & 4.69 & 4.19 & 3.53 & 92.15 & 79.66 & 316.16 & 0.8\end{array}$

$\begin{array}{llllllll}13: 13 & 4.68 & 4.19 & 3.64 & 92.12 & 79.83 & 332.07 & 0.8\end{array}$

$\begin{array}{llllllll}13: 18 & 4.68 & 4.20 & 3.61 & 92.06 & 79.92 & 325.09 & 0.8\end{array}$

$\begin{array}{llllllll}13.23 & 4.68 & 4.20 & 3.34 & 92.04 & 80.04 & 294.80 & 0.8\end{array}$

$\begin{array}{llllllll}13: 28 & 4.68 & 4.20 & 3.72 & 91.99 & 80.04 & 337.78 & 0.8\end{array}$

$\begin{array}{llllllll}13: 33 & 4.68 & 4.20 & 3.71 & 91.99 & 80.00 & 337.25 & 0.8\end{array}$

$\begin{array}{llllllll}13: 38 & 4.68 & 4.20 & 3.75 & 91.97 & 80.09 & 343.95 & 0.8\end{array}$

$\begin{array}{llllllll}13: 43 & 4.68 & 4.20 & 3.74 & 91.96 & 80.09 & 345.52 & 0.8\end{array}$

$\begin{array}{llllllll}13: 48 & 4.68 & 4.21 & 3.68 & 91.96 & 80.17 & 335.90 & 0.8\end{array}$

$\begin{array}{llllllll}13: 53 & 4.68 & 4.21 & 3.89 & 91.91 & 80.31 & 363.41 & 0.8\end{array}$

$\begin{array}{llllllll}13: 58 & 4.67 & 4.21 & 3.76 & 91.85 & 80.23 & 345.31 & 0.8\end{array}$

$\begin{array}{llllllll}14: 03 & 4.67 & 4.21 & 3.81 & 91.85 & 80.15 & 352.57 & 0.8\end{array}$

$\begin{array}{llllllll}14: 08 & 4.67 & 4.20 & 3.38 & 91.85 & 80.12 & 298.56 & 0.8\end{array}$

$\begin{array}{llllllll}14: 13 & 4.68 & 4.2 \mathrm{I} & 3.53 & 91.88 & 80.16 & 315.19 & 0.8\end{array}$

$\begin{array}{llllllll}14: 18 & 4.67 & 4.21 & 3.63 & 91.87 & 80.23 & 327.74 & 0.8\end{array}$

$\begin{array}{lllll}14: 23 & 4.67 & 4.21 & 3.59 & 91.86\end{array}$

$\begin{array}{lllll}14: 28 & 4.67 & 4.21 & 3.39 & 91.82\end{array}$

$80.21 \quad 322.94$

$\mathbf{8 0 . 2 0} 296.81$

$\begin{array}{lllll}14: 33 & 4.67 & 4.20 & 3.33 & 91.81\end{array}$

$\begin{array}{lllll}14: 38 & 4.67 & 4.20 & 3.51 & 91.84\end{array}$

$80.12 \quad 291.80$

$80.11 \quad 316.08$

$\begin{array}{lllllll}14: 43 & 4.67 & 4.20 & 3.64 & 91.82 & 80.03 & 330.41\end{array}$

$\begin{array}{lllllll}14: 48 & 4.67 & 4.20 & 3.61 & 91.87 & 80.03 & 326.76\end{array}$

$\begin{array}{lllllll}14: 03 & 4.67 & 4.20 & 3.94 & 91.86 & 79.97 & 366.35\end{array}$

$\begin{array}{lllllll}14: 58 & 4.67 & 4.19 & 3.57 & 91.83 & 79.83 & 322.46\end{array}$

\begin{tabular}{lllllll|}
$15: 03$ & 4.67 & 4.19 & 3.23 & 91.87 & 79.65 & 277.55 \\
15.08 & 4.68 & 4.19 & 2.50 & 91.95 & 79.63 & 187.51
\end{tabular}

$\begin{array}{lllllll}15: 13 & 4.68 & 4.19 & 2.20 & 91.95 & 79.70 & 149.91\end{array}$

$\begin{array}{lllllll}15: 18 & 4.68 & 4.19 & 1.98 & 91.94 & 79.80 & 121.49\end{array}$

$\begin{array}{lllllll}15: 23 & 4.68 & 4.20 & 1.90 & 91.90 & 79.88 & 112.84\end{array}$

$\begin{array}{lllllll}15: 28 & 4.67 & 4.19 & 1.83 & 91.85 & 79.79 & 103.92\end{array}$

Ran out of N2

Page 10 of 13 


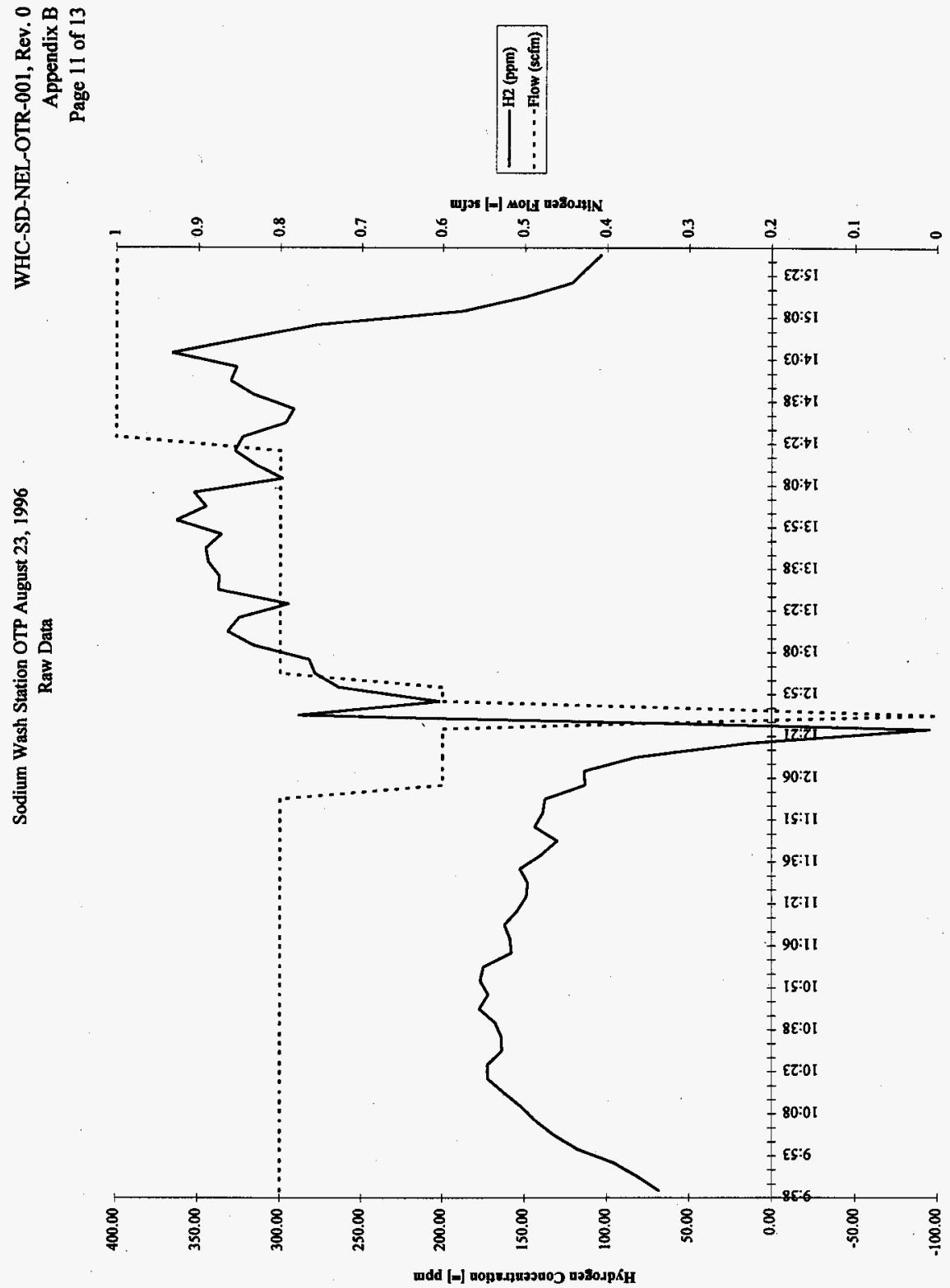




\begin{tabular}{|c|c|c|c|c|c|c|c|c|}
\hline Time & Temp (V) & Hum (V) & $\mathrm{H} 2(\mathrm{~V})$ & Temp (F) & $\operatorname{Hum}(\%)$ & $\mathrm{H} 2$ (ppm) & Flow (scfm) & Notes \\
\hline $9: 30$ & 4.51 & 4.18 & 2.10 & 87.68 & 79.55 & 137.05 & 1 & Flow initiated through \\
\hline $9: 35$ & 4.51 & 4.20 & 2.15 & 87.68 & 80.01 & 143.79 & 1 & moisture column at 0820 . \\
\hline $9: 40$ & 4.51 & 4.22 & 2.06 & 87.70 & 80.41 & 132.74 & 1 & \\
\hline $9: 45$ & 4.51 & 4.23 & 2.15 & 87.70 & 80.74 & 143.42 & 1 & \\
\hline 9:50 & 4.51 & 4.24 & 2.11 & 87.69 & 81.01 & 138.15 & 1 & \\
\hline $9: 55$ & 4.51 & 4.25 & 2.07 & 87.71 & 81.30 & 135.19 & 1 & \\
\hline $10: 00$ & 4.51 & 4.26 & 1.98 & 87.73 & 81.59 & 124.22 & 1 & \\
\hline $10: 05$ & 4.51 & 4.27 & 1.95 & 87.73 & 81.84 & 119.46 & 1 & \\
\hline $10: 10$ & 4.51 & 4.28 & 1.90 & 87.73 & 82.06 & 112.02 & 1 & \\
\hline $10: 15$ & 4.51 & 4.29 & 1.90 & 87.72 & 82.31 & 113.35 & 1 & \\
\hline $10: 20$ & 4.51 & 4.30 & 1.82 & 87.63 & 82.41 & 103.58 & 1 & \\
\hline $10: 25$ & 4.50 & 4.29 & 1.74 & 87.60 & 82.37 & 92.40 & 1 & \\
\hline $10: 30$ & 4.50 & 4.30 & 1.75 & 87.62 & 82.41 & 97.03 & 1 & \\
\hline $10: 35$ & 4.50 & 4.30 & 1.73 & 87.59 & 82.48 & 90.18 & 1 & \\
\hline $10: 40$ & 4.50 & 4.30 & 1.65 & 87.59 & 82.55 & 80.66 & 1 & \\
\hline $10: 45$ & 4.50 & 4.30 & 1.46 & 87.56 & 82.62 & 56.81 & 1 & \\
\hline $10: 50$ & 4.50 & 4.31 & 1.25 & 87.54 & 82.71 & 30.90 & 1 & \\
\hline $10: 55$ & 4.50 & 4.31 & 1.20 & 87.54 & 82.80 & 25.10 & 1 & \\
\hline 11:00. & 4.50 & 4.32 & 1.15 & 87.54 & 82.93 & 19.16 & 1 & \\
\hline 11:05 & 4.50 & 4.32 & 1.06 & 87.53 & 83.08 & 7.72 & 1 & \\
\hline $11: 10$ & 4.50 & 4.33 & 1.06 & 87.52 & 83.22 & 8.61 & 1 & \\
\hline $11: 15$ & 4.50 & 4.33 & 1.06 & 87.51 & 83.35 & 7.52 & 1 & \\
\hline $11: 20$ & 4.50 & 4.34 & 1.09 & 87.49 & 83.49 & 11.23 & 1 & \\
\hline $11: 25$ & 4.50 & 4.35 & 1.09 & 87.48 & 83.64 & 11.01 & 1 & \\
\hline $11: 30$ & 4.50 & 4.35 & & 87.45 & 83.84 & -5.22 & 1 & \\
\hline 11:35 & 4.50 & 4.36 & 1.00 & 87.46 & 84.00 & 1.04 & 1 & \\
\hline $11: 40$ & 4.50 & 4.37 & & 87.43 & 84.18 & -0.88 & 1 & \\
\hline $11: 45$ & 4.50 & 4.38 & & 87.42 & 84.38 & -12.38 & 1 & \\
\hline $11: 50$ & 4.50 & 4.38 & & 87.39 & 84.61 & -8.22 & 1 & \\
\hline 11:55 & 4.49 & 4.39 & 1.01 & 87.35 & 84.80 & 2.80 & 0.2 & Hydrogen concentration 0 . \\
\hline $12: 00$ & 4.49 & 4.40 & 2.22 & 87.29 & 84.95 & 149.77 & 0.2 & Reduced flow to determine \\
\hline $12: 05$ & 4.49 & 4.40 & 1.69 & 87.29 & 85.11 & 87.51 & 0.2 & reaction completion. \\
\hline $12: 10$ & 4.49 & 4.41 & 1.58 & 87.24 & 85.22 & 75.67 & 0.2 & \\
\hline $12: 15$ & 4.49 & 4.41 & 1.31 & 87.19 & 85.33 & 38.96 & 0.2 & \\
\hline $13: 20$ & 4.49 & 4.42 & 1.21 & 87.18 & 85.42 & 24.39 & 0.2 & \\
\hline $12: 25$ & 4.49 & 4.42 & 1.14 & 87.17 & 85.54 & 17.11 & 0.2 & \\
\hline $12: 30$ & 4.49 & 4.43 & 1.13 & 87.13 & 85.69 & 17.57 & 0.2 & \\
\hline $12: 35$ & 4.48 & 4.43 & 1.16 & 87.06 & 85.81 & 19.96 & 0.2 & \\
\hline $12: 40$ & 4.48 & 4.44 & 1.09 & 87.06 & 85.88 & 11.24 & 0.2 & \\
\hline $12: 45$ & 4.48 & 4.44 & 1.08 & 87.03 & 85.97 & 10.32 & 0.2 & Looked inside segment, \\
\hline $12: 50$ & 4.48 & 4.44 & 3.43 & 87.02 & 86.08 & 289.70 & 0.2 & couldn't see any $\mathrm{Na}$. \\
\hline $12: 55$ & 4.48 & 4.45 & 2.15 & 86.98 & 86.16 & 139.04 & 0.2 & \\
\hline $13: 00$ & 4.48 & 4.45 & 1.27 & 86.94 & 86.22 & 33.39 & 0.2 & \\
\hline 13:05 & 4.48 & 4.45 & 1.22 & 86.93 & 86.27 & 29.10 & 0.2 & Checked calibration, \\
\hline $13: 10$ & 4.48 & 4.45 & 1.40 & 86.93 & 86.32 & 50.36 & 0.2 & correction required. \\
\hline $13: 15$ & 4.48 & 4.46 & 4.10 & 86.97 & 86.48 & 390.39 & 0.2 & Flow dropped below 0.2 \\
\hline $13: 20$ & 4.47 & 4.46 & 4.65 & 86.80 & 86.43 & 456.22 & 0.2 & scfm. \\
\hline $13: 25$ & 4.47 & 4.43 & 3.06 & 86.71 & 85.86 & 248.54 & 0.2 & \\
\hline $13: 30$ & 4.47 & 4.40 & 1.21 & 86.68 & 85.10 & 26.09 & 0.2 & \\
\hline $13: 35$ & 4.47 & 4.37 & 1.22 & 86.71 & 84.23 & 27.47 & 0.2 & \\
\hline $13: 40$ & 4.47 & 4.34 & 1.18 & 86.75 & 83.37 & 22.54 & 0.2 & \\
\hline $13: 45$ & 4.47 & 4.30 & 1.23 & 86.79 & 82.57 & 29.89 & 0.2 & \\
\hline 13:50 & 4.47 & 4.28 & 1.15 & 86.85 & 81.87 & 19.11 & 0.2 & \\
\hline
\end{tabular}



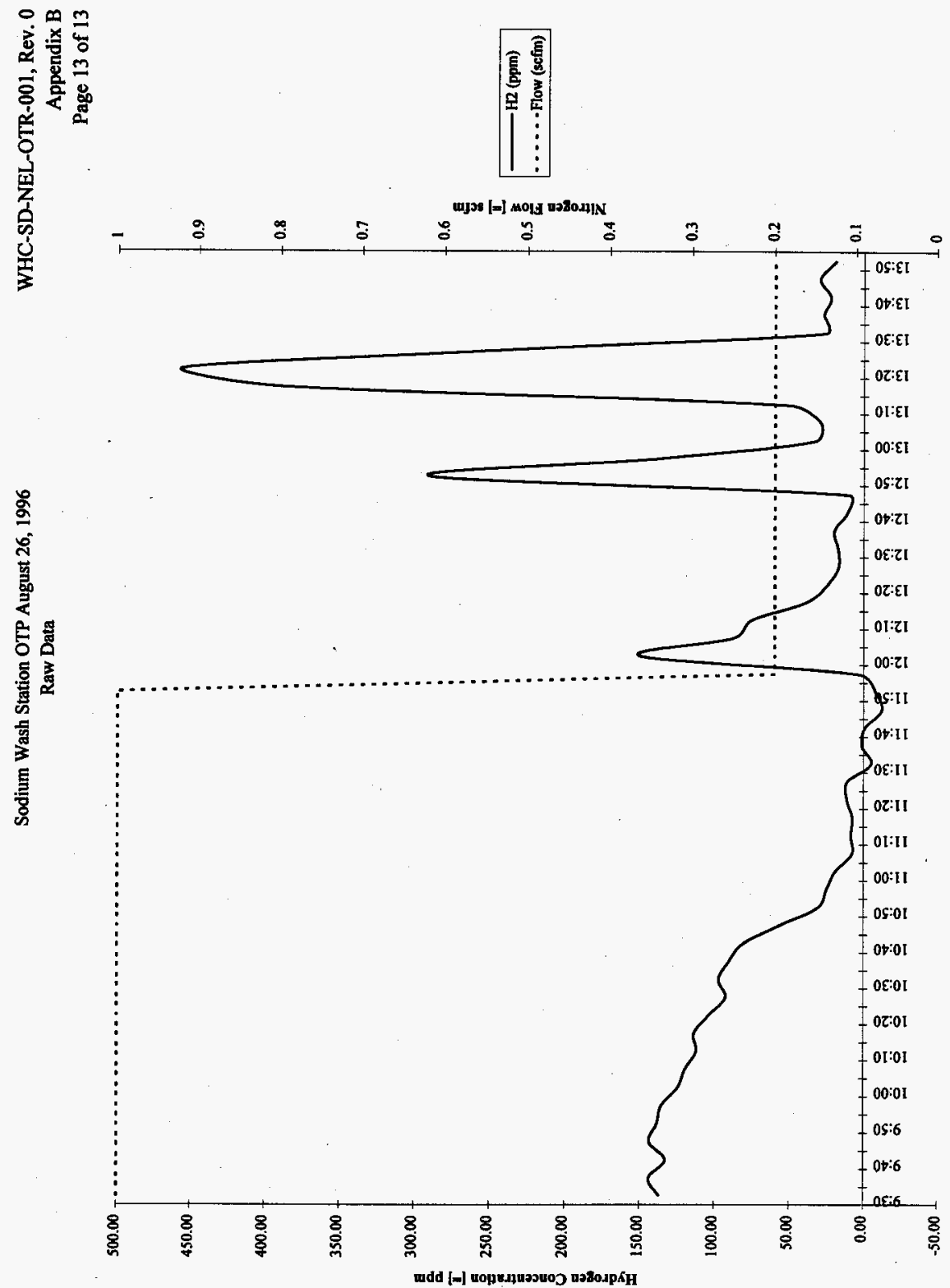


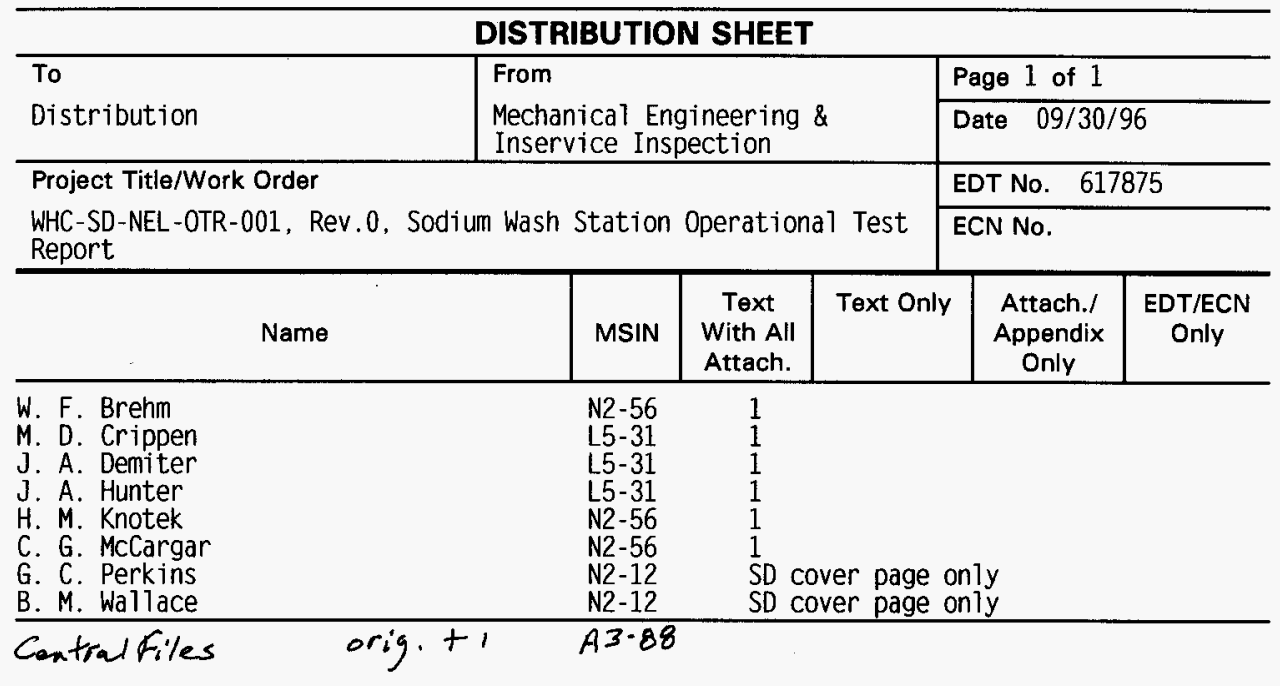

